WP 15-20

\author{
Andros Kourtellos \\ University of Cyprus, Cyprus \\ The Rimini Centre for Economic Analysis, Italy
}

Charalambos G. Tsangarides

International Monetary Fund, USA

\title{
ROBUST CORRELATES OF GROWTH SPELLS: DO INEQUALITY AND REDISTRIBUTION MATTER?
}

Copyright belongs to the author. Small sections of the text, not exceeding three paragraphs, can be used provided proper acknowledgement is given.

The Rimini Centre for Economic Analysis (RCEA) was established in March 2007. RCEA is a private, nonprofit organization dedicated to independent research in Applied and Theoretical Economics and related fields. RCEA organizes seminars and workshops, sponsors a general interest journal The Review of Economic Analysis, and organizes a biennial conference: The Rimini Conference in Economics and Finance (RCEF) . The RCEA has a Canadian branch: The Rimini Centre for Economic Analysis in Canada (RCEACanada). Scientific work contributed by the RCEA Scholars is published in the RCEA Working Papers and Professional Report series.

The views expressed in this paper are those of the authors. No responsibility for them should be attributed to the Rimini Centre for Economic Analysis. 


\title{
Robust Correlates of Growth Spells: Do Inequality and Redistribution Matter?*
}

\author{
Andros Kourtellos ${ }^{\dagger} \quad$ Charalambos G. Tsangarides ${ }^{\ddagger}$
}

April 29, 2015

\begin{abstract}
Theoretical and empirical evidence on inequality and growth provides only partial guidance about the relationship. Much of the problem stems from model uncertaintyabout what covariates to use, the relationships between them, and the transmission mechanisms-which is often not properly accounted for. This paper investigates the relationship between growth, redistribution, and the duration of growth spells in the presence of a rich set of alternative determinants and theories using model averaging for duration models to account for model uncertainty. We find that lower net inequality is robustly correlated with longer growth spells, while redistribution appears generally benign for growth spells, but the effect is not robust. In addition, there is no evidence of nonlinearities in the inequality-redistribution-growth spell relationship. Finally, lower initial income, higher secondary education and higher FDI are associated with longer spell duration.
\end{abstract}

Keywords: inequality, duration analysis, model averaging, growth sustainability.

JEL Classification Codes: O11, O40, C11

*The views expressed in this manuscript are those of the authors and do not necessarily represent those of the IMF or IMF policy.

${ }^{\dagger}$ Department of Economics, University of Cyprus, P.O. Box 537, CY 1678 Nicosia, Cyprus, e-mail: andros@ucy.ac.cy.

${ }^{\ddagger}$ Research Department, International Monetary Fund, 700 19th Street NW, Washington DC 20431, USA, e-mail: ctsangarides@imf.org. 


\section{Introduction}

In developed and developing countries alike, the poorest half of the population often controls less than $10 \%$ of its wealth.

[World Economic Forum: Outlook on the Global Agenda 2015]

Will we accept an economy where only a few of us do spectacularly well? Or will we commit ourselves to an economy that generates rising incomes and chances for everyone who makes the effort?

[President Barack Obama State of the Union address January 20, 2015]

Recent evidence on income inequality shows that on average income inequality exhibits a rising trend in most countries, especially for the group of high-income countries. A prime example is the U.S., where according to Saez (2015) income inequality has increased dramatically over the last twenty-five years and reached the highest level since 1917.

These alarming trends have generated debates among policy makers, activists, and academics about the implications of income inequality and redistribution on economic wellbeing. For example, Rajan (2010) argues that rising inequality in the form of expanded lending to households resulted in a credit boom and eventually to the global financial crisis. Stiglitz (2013) examines how political-economy factors such as political power by moneyed interests produces a two-tiered society and inequality, which, in turn, creates volatility, fuels

crises, and retards growth. More recently, Piketty (2014) shows how extreme inequalitydriven by the fact that returns on capital exceed the rate of economic growth-can stir political instability and undermines democratic values. The latter view is also shared by Stiglitz, who 
argues that society pays a high price for this inequality in terms of our democracy and that economic inequality inevitably translates into political inequality.

Economic theory does not provide concrete guidance in resolving the debate. Many channels through which income inequality can affect economic growth are possible. The classical approach argues that an uneven distribution of incomes can be beneficial for subsequent growth through the savings or investment mechanism (Kaldor (1967)). If the marginal saving rates are inversely related to the level of income, then higher inequality implies that the rich would have higher savings rates, which leads to more investment and growth.

Other theoretical models show how increases in inequality lead to lower rates of growth (Galor (2009)). One set of arguments is based on political economy and credit market imperfections. For example, Alesina and Rodrik (1994) and Persson and Tabellini (1994) provide a fiscal policy explanation by suggesting that high income inequality may retard growth by generating political demands for redistribution policies that result in distortions that adversely affect investment in physical and human capital, respectively. Saint-Paul and Verdier (1996) provide an alternative political economy explanation. They argue that in unequal societies efficient redistribution policies are prevented because the decisive voter is the rich and not median voter. Furthermore, Alesina and Perotti (1996) argue that societies with very unequal distribution of wealth are more likely to experience social tensions and discontent, and increase socio-political instability, which create disincentives to investment and results in lower growth. Borrowing constraints stemming from credit market imperfections prevent people lacking financial means to invest in human and physical capital. This leaves unexploited opportunities for investment, decreases the stock of physical and human capital, and reduces growth (Perotti (1996); Galor and Moav (2004)). Galor and Zeira (1993) show that in the presence of credit market imperfections 
along with fixed costs associated with investment in education, inequality affects occupational choices that lead to under-investment in growth-enhancing activities. More recently, Galor and Moav (2004) propose a unified theory of the implications of inequality on the growth process, which demonstrates that the effect of inequality on growth depends on the relative return to physical and human capital. When the relative return to physical capital is high, inequality is beneficial for growth while when the relative return to human capital is high, inequality is harmful for growth.

Another important channel by which inequality may affect growth is the fiscal policy channel (e.g., Persson and Tabellini (1994); Perotti (1996)), in which high inequality may generate pressures for distortionary fiscal redistribution that itself reduces long-term growth. One part of the argument is that higher inequality will create pressures for redistributionthe median voter has less income than the mean which creates an incentive to vote for more redistribution (Meltzer and Richard (1981)). The direct effect of redistribution on growth centers on the apparent trade-off between equity and efficiency-distributing resources and benefits throughout society more equitably or allowing the optimal production and allocation of resources. Redistribution in the form of progressive taxation may distort incentives to gain wealth, or perceived ineffectiveness of redistributive policies and allocation of resources raises transaction costs and some loss in efficiency in the redistribution process (Okun (1975)). This distortionary effect of progressive taxation (the "excess burden") may (or may not) be compensated by the redistribution effects (Alesina and Rodrik (1994) and Persson and Tabellini (1996)).

Surveying the empirical evidence, we find, remarkably, little consensus on the relationships between growth, inequality, and redistribution. On the relationship between inequality and growth, the evidence generally supports the view that more unequal income distributions tended to grow slower (e.g., Alesina and Rodrik (1994) and 
Persson and Tabellini (1994)) Bebabou, 1996; Perotti, 1996). Subsequent studies, typically exploring the panel dimension of the data, find evidence that the relationship is likely to depend on the stage of the country's economic development, and the time horizon considered (Forbes (2000), Panizza (2002), and Halter, Oechslin, and Zweimüller (2014)). There is also some evidence of nonlinear relationship between inequality and growth (e.g., Barro (2000); Banerjee and Duflo (2003)). However, the evidence on the relationship between growth and redistribution is not robust and often depends on the indicators used to proxy for redistribution and the specification (e.g., Tanzi and Zee (1997)). For example, Romer and Romer (2010) and Afonso and Furceri (1997) find that, in general, taxes or government spending negatively affect growth. In contrast, Lindert (2004) finds that public spending in education and infrastructure spending is not detrimental for growth while Boadway and Keen (2000) find that some public policies with redistributing effects may facilitate growth by providing social insurance and safety nets.

We posit that there are two major reasons for the lack of consensus on the relationship between inequality, redistribution, and growth. First, cross-country growth investigations typically fail to properly account for model uncertainty which often leads to fragile inferences about the role of the variables of interest such as inequality and redistribution. As argued by Brock and Durlauf (2001) and others, growth theories are inherently open-ended, as they admit a broad number of possible specifications which tend to be non-mutually exclusivethat is, one growth theory has no impact on whether another theory is empirically important or not. Accounting for model uncertainty is particularly important for the purposes of our investigation. We need a framework that allows all possible channels of transmission to operate. For example, the hypothesis that inequality and/or redistribution affect the growth process does not preclude an alternative theory, such as institutions or the role of macroeconomic policy, from also being a possible explanation. In addition, as discussed 
above, economic theory does not provide definite conclusions about the relationships between inequality, redistribution, and growth, and there is little theoretical guidance as to what the relevant theories and determinants are.

The second problem is the unit of analysis. Existing empirical studies generally put the emphasis on explaining the overall average growth rate, thus ignoring the substantial variation in the volatility of growth. For example, advanced and some emerging markets grow fairly consistently, while most developing countries alternate between periods of very fast growth and stagnation or decline. Emphasis on the average growth rate also ignores the substantial heterogeneity in the duration of growth episodes 1 For example, Pritchett (2000) argues that trying to explain average cross-country growth differences can be misleading because economic growth does not follow smooth patterns but often abruptly switches between persistent periods of steady and rapid growth ("hills"), steady and rapid growth followed by declines ("mountains"), steady declines ("valleys"), catastrophic falls ("cliffs"), or flat growth rates ("plateaus") as in Figure 1. Attempts to explain turning points in these patterns of growth include Pritchett (2000), Hausmann. Rodriquez. and Wagner (2006), Hausmann. Prichett. and Rodrik (2005), Jerzmanowski (2006), Jones and Olken (2008), Aizenman and Spiegel (2010), and Berg, Ostry, and Zettelmeyer (2012). Since explaining growth turning points may be different from what is needed to keep growth going, our investigation examines the relationship between inequality, redistribution, and growth by focusing squarely on episodes of sustained growth.

Our paper contributes to the existing literature by addressing the aforementioned problems. In particular, we propose a novel approach that focuses on growth spells in order to assess the strength of the relationship between inequality, redistribution, and the duration of growth spells by explicitly accounting for model uncertainty using a model averaging

\footnotetext{
${ }^{1}$ While panel regressions can potentially help address some of these issues, they still fail to capture the turning points in the growth process, and the different timing of turning points across countries.
} 
methodology. Methodologically we proceed as follows. First, following Jones and Olken (2008), Berg. Ostry, and Zettelmever (2012), and Kerekes (2011) we identify growth spells by employing the Bai-Perron methodology, which estimates and tests for multiple breaks, as well as an economic "filter". We then define a growth spell as a period of high growth following a growth up-break and ending either with a growth down-break or with the end of the sample. Second, we employ Bayesian Model Averaging (BMA) for Cox hazards models to assess the relative importance of alternative growth theories. Importantly, we extend the BMA method developed by Volinsky, Madigan, Raftery, and Kronmal (1997) to allow for time-dependent covariates in order to properly account for the time-varying feedback effect of the variables on the duration of growth spells. BMA has successfully accounted for model uncertainty in the context of growth regressions by constructing estimates conditional not on a single model, but on a model space whose elements span an appropriate range of determinants suggested by a large body of work (e.g., Brock and Durlauf (2001), Fernandez, Lev, and Steel (2001), Sala-i Martin. Doppelhofer, and Miller (2004), Durlauf. Kourtellos, and Tan (2008), Malik and Temple (2009), and Mirestean and Tsangarides (2015)). Our paper is closely related to a recent study by Ostry, Berg, and Tsangarides (2014) who also consider the impact of inequality and redistribution on the duration of growth episodes. One important difference between Ostry, Berg, and Tsangarides (2014) and the current study is that the former does not formally address the impact of model uncertainty.

Our main findings can be summarized as follows. First, lower net inequality is strongly and robustly correlated with longer growth spells, controlling for the effect of redistribution. This suggests that the inequality-growth relationship is not due to the impact of inequality on redistribution. Second, redistribution does not appear to be robustly correlated with the duration of growth spells but it is effect is generally benign, thus rejecting Okun's assertion of a trade-off between redistribution and growth. As a result, the combined direct and 
indirect effects of redistribution, including the effects of the resulting lower inequality are spell-preserving. Third, we find no evidence of nonlinearities in the inequality-redistributiongrowth spell relationship. Therefore, the growth-inequality relationship does not depend on the extent of inequality, while redistributive policies, irrespective of their magnitude, are generally benign for growth spells. Finally, in addition to inequality we find robust evidence for three additional variables; lower initial income, higher secondary education and higher FDI are associated with longer spell duration.

The rest of the paper is organized as follows. Section 2 describes the duration analysis. Section 3 describes the dataset including the construction of growth spells. Section 4 describes the BMA method and Section 5 discusses the empirical results. Finally, Section 6 concludes.

\section{Hazards Regression for Spells}

The focus of our paper is to investigate how income inequality $\left(I N E Q_{i t}\right)$ and redistribution $\left(R E D_{i t}\right)$ affect the probability of the event that a country's relatively high economic growth period, which we define as a growth spell, comes to an end. Put differently, we are interested in investigating whether the "waiting" time (duration) during which a country remains in a spell is correlated with income inequality and redistribution.

In particular, we assume that countries $i=1, \ldots, n$ enter a state of growth spell at time $\tau_{t}$ and leave at time $\tau_{t+1}$. Define the duration of this spell as the random variable $T_{i}$ and let its realization be denoted by $t_{i}$, which takes a value in $\left\{t_{1}=\tau_{2}-\tau_{1}, t_{2}=\tau_{3}-\tau_{2}, \ldots\right\}$. Define the $p \times 1$ vector of regressors, $X_{i t-1}=\left(I N E Q_{i t-1}, R E D_{i t-1}, Z_{i t-1}^{\prime}\right)^{\prime}$, where $Z_{i t-1}$ is a vector of other country characteristics. Denote the cumulative distribution and probability density functions of $T_{i}$ conditional on $X_{i t-1}$ by $F_{T_{i} \mid X_{i t-1}}\left(t_{i}\right)=P\left(T_{i} \leq t_{i} \mid X_{i t-1}\right)$ and 
$f_{T_{i} \mid X_{i t-1}}\left(t_{i}\right)$, respectively. Conditional on $X_{i t-1}$ the survival function of $T_{i}$ is defined as $S_{T_{i} \mid X_{i t-1}}\left(t_{i}\right)=1-F_{T_{i} \mid X_{i t-1}}\left(t_{i}\right)$, which gives the probability that a spell has not ended by duration $t_{i}$. We focus on the rate at which a country leaves the state at duration $t_{i}$ given that it has not done so yet. Specifically, conditional on $X_{i t-1}$, the probability that the growth spell is completed at $t_{i}$ given it has not been completed before $t_{i}$ is defined by the hazard function

$$
\lambda\left(t_{i} \mid X_{i t-1}\right)=P\left(T_{i}=t_{i} \mid T_{i} \geq t_{i}, X_{i t-1}\right)=\frac{f_{T_{i} \mid X_{i t-1}}\left(t_{i}\right)}{S_{T_{i} \mid X_{i t-1}}\left(t_{i}\right)}
$$

The value of the hazard function for specific $t_{i}$ is called the hazard rate. The hazard rate is a measure of risk in the sense that higher hazard rates correspond to higher risks of transitioning out of the growth and hence implying a shorter spell.

In particular, we employ the Cox hazards model

$$
\lambda\left(t_{i} \mid X_{i t}\right)=\lambda_{0}\left(t_{i}\right) \exp \left(\beta_{I} I N E Q_{i t}+\beta_{R} R E D_{i t}+\beta_{Z}^{\prime} Z_{i t}\right),
$$

where $\lambda_{0}\left(t_{i}\right)$ is the time dependent part known as the baseline hazard function that describes the countries' risk for transitioning if their risk was independent of their characteristics. The objects of interest are the coefficients $\beta_{I}$ and $\beta_{R}$ which measure the contribution of the inequality and redistribution to the relative change in hazard ratios. For example, a one standard deviation increase in inequality increases or decreases the hazard of ending the growth spell by $\exp \left(\beta_{I}\right)-1$ percentage points depending on whether the $\beta_{I}$ coefficient is positive or negative, respectively. 


\section{Data}

Our dataset takes the form of an unbalanced annual panel for the period 1950-2010 and 153 countries. A detailed description of the data and our sources is given in the Data Appendix A1. Our unit of analysis (the duration variable) is a growth spell, defined as a period of high growth following a growth up-break and ending either with a growth down-break or with the end of the sample. A growth spell is constructed in two steps.

First, following Antoshin, Berg, and Souto (2008) we employ a variant of the Bai and Perron (1998) procedure to test for multiple structural breaks in time series when both the total number and the location of breaks are unknown. Second, we employ an economic filter to the identified structural breaks as proposed by Berg. Ostry, and Zettelmeyer (2012) to identify spells in economic growth in 153 countries for which internationally comparable output data are available using version 7.1 of the Penn World Tables. We discuss the details of these two steps below.

\subsection{Structural Breaks}

For each country $i$, we investigate the presence of $m$ breaks in the simple constant growth model

$$
g_{i t}=\alpha_{i j}+e_{i t}
$$

where $t=T_{j-1}+1, \ldots, T_{j}$ and $j=1, \ldots, m+1, T_{0}=0$ and $T_{m+1}=T \cdot g_{i t}$ denotes the annual growth rate of real GDP per capita for country $i$ in year $t, \alpha_{i j}$ is the mean growth rate during growth in regime $j$, and $e_{i t}$ is error term of country $i$ at time $t$. The break points $T_{1}, \ldots T_{m}$ are treated as unknown and estimated by minimizing the sum squared errors of the constant growth model given a maximum number of breaks. Then, a sequential testing procedure 
is implemented to determine the required number of break points. The procedure requires defining the minimum years between breaks $h$, which effectively determines the maximum number of breaks for each country.

Table 1 shows the distribution of the identified breaks for per capita growth rates. We group "upbreaks" and "downbreaks" by region, and for breaks not closer than 5 or 8 years. We begin with some descriptive statistics. With 5 years between breaks, 157 upbreaks and 164 downbreaks are identified. As expected, lower values of $h$ result in more identified breaks; restricting the minimum length of spell to 8 years decreases the total number of breaks by about $30 \%$ compared to the 5 year minimum. 2

Despite these differences, the choice of $h$ does not substantially affect the distributions of upbreaks and downbreaks. For example, irrespective of the method defining the breaks, about one-third of either upbreaks or downbreaks occur in Africa, $8 \%$ of upbreaks breaks occur in advanced countries, and, broadly speaking, average break sizes are comparable across regions. Downbreaks are at least twice as frequent as upbreaks in advanced countries, while upbreaks are more common than downbreaks in Asia. There is substantial regional variation in the distribution of upbreaks and downbreaks by country group and across decades. On average, upbreaks across groups tend to be most common in the 1950-60s, and 1990s. For the 1950- 60s Latin American and Caribbean countries experienced the most upbreaks, while Africa accounts for about $40 \%$ of the upbreaks in the 1990s. In contrast, downbreaks are more frequent in the 1970s and mostly occur in advanced countries and Africa. Latin America had most of its downbreaks in the 70s and 80s.

\footnotetext{
${ }^{2}$ In general, allowing for a shorter frequency for spells may pick up abrupt output movements reflecting volatility or business cycles, but, at the same time, larger frequencies may miss smaller or shorter-lived spells. Also, allowing higher critical values could increase the total number of breaks identified, but this comes at the expense of more "false positives" (that is, identifying a break when there is none).
} 


\section{$3.2 \quad$ Spells}

Using the identified upbreaks and downbreaks we follow Berg, Ostry, and Zettelmeyer (2012) to define "complete" growth spells as periods of time that (i) begin with a growth upbreak followed by a period of at least $2 \%$ average per capita income growth; and (ii) end with a growth downbreak followed by a period of less than $2 \%$ average per capita income growth. Similarly, incomplete growth spells can be defined as those that satisfy condition (i) and are still on-going at the end of the sample.

Table 2 examines the frequency and duration of growth spells and some stylized facts. Most growth spells occur in Africa (about a third of all spells which is roughly the share of those countries in the sample), while the fewest spells (about $10 \%$ of total spells) occur in advanced countries. While it is not unusual to get a growth spell started, countries differ in their ability to sustain the spell for longer periods: compared to other regions, African and Latin American and Caribbean countries have the lowest mean length of growth spells, while on average, complete spells in Asia last for about 16 years. Spells in Asia are not just more likely to last longer on average; it is also the case that most spells in Emerging Asia also last longer: $38 \%$ of complete spells in Emerging Asia last at least 16 years, compared to $25 \%$ in industrialized and $9 \%$ in Latin American and Caribbean countries. Africa has the fewest spells lasting 10 years (22\%) while no spell in Africa lasts for more than 16 years.

What is the growth experience before, during, and after the end of spells? Table 3 shows that spells in advanced countries tend to start from much higher per capita growth rates than those in other countries whose spells tend to begin from negative growth rates, on average. Overall, growth rates during spells are relatively similar across all regions except Africa: growth during spells is about 3.5\% higher in Africa compared to the rest of the world. Perhaps the most sticking differences are in the growth rates after the growth spells 
end. On average, growth after the end of a complete spell is about $1 \%$ in advanced countries when the spell ends and $0.4 \% 3$ years after the end of the spell suggesting a "soft landing." In contrast, in Africa and Middle East, growth after the end of a spell is about $-2.5 \%$, while three years after the end of the spell growth is even lower $(-2.7 \%)$.

Given the focus of our paper, we now turn to some stylized facts about the relationship between the duration of growth spells, inequality, and redistribution. Table 4 shows how average inequality and redistribution evolve before, during, and after spells. Across all groups, average inequality improves during spells and rises after the end of spells; in most cases, just 3 years after the end of the spell inequality reaches or exceeds the pre-spell levels. Since average growth rises during spells (and is lower after the end of spells), this suggests that growth and inequality improvements are positively correlated. There is substantial variation across regions, with the Africa and Asia registering the most improvements in inequality during spells (3 and 7 percentage points, respectively) while advanced countries experience more modest inequality improvements during the spell. On average, redistribution falls during spells (when growth rises and inequality falls) in all regions except the advanced countries. Figure 2 represents the unconditional relationship between the duration of growth spells, inequality, and redistribution. Three things stand out. First, more equal societies that redistribute less tend to experience longer spells. Second, slicing the graph in two dimensions, countries with lower inequality experience longer spells while countries that redistribute less end up with longer spells. Finally, the relationship between spell duration, inequality, and redistribution appears non-linear.

Overall, the descriptive statistics suggest that there is substantial heterogeneity in the spell sample as well as possible non-linearities in the relationships. In our estimation section, we discuss how we take account of heterogeneity and address potential non-linearities 3 Also,

\footnotetext{
${ }^{3}$ Focusing explicitly on parameter heterogeneity, Tsangarides (2012) investigates whether determinants of growth spells operate differently in Africa than in the rest of the world.
} 
henceforth, our analysis will focus on the spells identified with $h=5$. This choice strikes a good balance between having a sufficient number of spells identified and adequate variation across countries for the effective sample in the robustness analysis 4

\subsection{Inequality, Redistribution and Additional Covariates}

Despite greater coverage across countries and over time from a variety of sources, cross country research on the causes and consequences of income inequality is hindered by the lack of comparability across data sources. A key question is how to extract information that is conceptually comparable across datasets? One way that has recently been suggested in the literature is to make datasets more comparable rather than discarding information.

Following Brückner, Gerling, and Grüner (2010) and Ostry, Berg, and Tsangarides (2014) we measure income inequality by the net gini coefficient and redistribution by the difference between the market and net inequality series based on Solt (2009). Solt (2009) uses a systematic method, a "custom missing-data algorithm" to addresses the non-comparability of the various surveys that underlie the data. The resulting database contains a set of standardized inequality variables that maximizes comparability for the largest possible sample of countries and years and is better suited for cross-national research on income inequality than previously available databases. It is also the only database that provides comparable net and market inequality across a broad sample of countries. The distinction is essential for the analysis of the relationship between inequality and growth as almost all the reasoning about the effects of inequality and growth is about the effects of net inequality-that is presumably what matters for political stability and social consensus 5

\footnotetext{
${ }^{4} \mathrm{As}$ also discussed in the descriptive statistics, the choice of $h$ makes little difference (if any) in the qualitative conclusions.

${ }^{5}$ Despite this, most data sets until recently combined net and gross inequality measures for different countries at different times. Also, part of the reason why there has been little attention to the joint effects of inequality, redistribution, and growth is the lack of comparable data on both net and market inequality
} 
For the rest of the covariates in the analysis, and in the absence of strong theoretical guidance, we posit that the duration process shares the same information set as the process of economic growth. This suggests that the set of possible theories and their proxies that have been proposed in the empirical growth literature can also be used in the context of growth spells. In particular, we consider 23 determinants from 9 broad categories or theories of growth: Solow growth theory (e.g., Mankiw. Romer. and Weil (1992)), macroeconomic policy environment (e.g., Acemoglu. Johnson. Robinson. and Thaicharoen (2003)), ethnic fractionalization (e.g., Alesina, Baqir, and Easterlv (1999)), institutions (e.g., Acemoglu and Johnson (2005)), geography (e.g., Sachs, Gallup, and Mellinger (1999)), conflict (e.g., Collier and Rohner (2010)), macroeconomic shocks (e.g., Rodrik (1999)), market distortions (e.g. Perotti (1996), and intensity of the spell (e.g., Berg, Ostry, and Zettelmever (2012)).

The Solow determinants include the initial income per capita, population growth, investment to GDP, total primary education years, and total secondary education years. The macroeconomic policy theory includes both policy variables as well as exogenous shocks. Specifically, we include government spending to GDP, openness, $\log (1+$ inflation), external debt liabilities to GDP, FDI liabilities to GDP, and an index of exchange rate overvaluation. In terms of shocks, we include lagged terms of trade growth, lagged US interest rate change, and an index identifying a shock to terms of trade growth. For institutions we include polityIV variables democracy and executive constraints. For conflict we include a variables that measures intra- and inter-state conflict. We proxy market distortions by the ratio of price level of investment to price level of consumption. The intensity of spells is captured by a variable that measures the growth during the spell. Geography is proxied by LCR100km which is a measure of geographical isolation. Finally, we include a great

measures for a large number of countries, and as a result, neither inequality nor redistribution can be appropriately measured (see also Milanovic (2000)). 
moderation time dummy, a sub-Saharan Africa dummy, and a high income country dummy to capture unobserved time and regional heterogeneity. All covariates are measured with a lag.

\section{BMA for Hazards Regression}

The standard approach in duration analysis presents estimates from a baseline PH-Cox model in equation (2), and then reports a robustness analysis that investigates a few alternative specifications of covariates. Typically, one of these models is the "kitchen sink" or "full" model where the full set of variables is used in the estimation.

The problem is that the standard approach ignores the issue of model uncertainty and bases its inference on a single model, which includes a particular set of covariates. In effect, the researcher implicitly assumes that the reported model represents the data generating process accurately, effectively assuming that the reported model has generated the data with probability 1 . The results, therefore, rely on strong priors on the part of the econometrician regarding the correct specification of the model. But economic growth theory is only loosely connected to the question of sustainability. More importantly, as argued by Brock and Durlauf (2001) new growth theories are open-ended, which means that any given theory of growth does not logically exclude other theories from also being relevant. In the present context, theory uncertainty implies that there is no a priori justification for focusing on macroeconomic policy variables (e.g., inflation) and not on institutions (e.g., executive constraints).

To systematically address the issue of model uncertainty, we employ a Bayesian Model Averaging (BMA) approach by constructing estimates conditional not on a single model, but on a model space $\mathcal{M}=\left\{M_{1}, . ., M_{K}\right\}$ whose elements span an appropriate range of 
determinants suggested by a large body of work. We are totally agnostic about whether any of the particular growth regressors is in the true model, and, therefore, assign each regressor a 0.5 prior probability of being in the true model. The model space is composed of the set of all possible permutations of the above growth regressors and is consistent with approaches taken in the growth literature such as Fernandez. Ley, and Steel (2001) and Sala-i Martin. Doppelhofer, and Miller (2004).

Model averaging "integrates out" the uncertainty over models by taking the weighted average of model-specific estimates, where the weights reflect the evidentiary support for each model given the data, $D$, and which are constructed to be analogous to posterior model probabilities. Then the posterior distribution of $\theta$ given the data, $D$, is given by

$$
\widehat{\mu}(\beta \mid D)=\sum_{k=1}^{K} \widehat{\mu}\left(\beta \mid M_{k}, D\right) \widehat{\mu}\left(M_{k} \mid D\right)
$$

where $\widehat{\mu}\left(\theta \mid M_{k}, D\right)$ is the empirical posterior distribution of $\theta$ given a particular model $M_{k}$, and $\widehat{\mu}\left(M_{k} \mid D\right)$ is the empirical posterior probability of model $M_{k}$, which is an element of the model space $\mathcal{M}$. The former is a standard Bayesian object, which does not have a closed form expressions in the case of Cox-PH models. Following Volinsky, Madigan, Raftery, and Kronmal (1997) we use the maximum likelihood approximation $\widehat{\mu}\left(\theta \mid M_{k}, D\right) \approx \widehat{\mu}\left(\theta \mid M_{k}, \widehat{\theta}_{D, k}, D\right)$, where $\widehat{\theta}_{D_{k} k}$ is the partial likelihood estimator of the model parameter $\theta_{k}$ for a particular model $M_{k} 6$ The model weights, $\widehat{\mu}\left(M_{k} \mid D\right)$ are computed using the Bayes' rule, so that each weight is the product of the integrated likelihood of the data given a model and the prior probability for a model, $\widehat{\mu}\left(M_{k} \mid D\right) \propto \widehat{\mu}\left(D \mid M_{k}\right) \mu\left(M_{k}\right)$.

As standard in the literature, we assume a uniform (flat) model prior so that the prior probability that any variable is included in the true model is taken to be 0.5 .

\footnotetext{
${ }^{6}$ This posterior refers to the following integral $\mu\left(\theta \mid M_{k}, D\right)=\int \mu\left(\theta \mid \theta_{k}, M_{k}, D\right) \mu\left(\theta_{k} \mid M_{k}, D\right) d \theta_{k}$, where $\mu\left(\theta \mid \theta_{k}, M_{k}, D\right)$ is the likelihood and $\mu\left(\theta_{k} \mid M_{k}, D\right) d \theta_{k}$ is the prior density of $\theta_{k}$.
} 
The integrated likelihood of model $M_{k}$ is approximated by the Bayesian information criterion (BIC), $\log \widehat{\mu}\left(D \mid M_{k}\right)=\log \widehat{\mu}\left(D \mid \widehat{\beta}_{D, k}, M_{k}\right)-(p / 2) \log n+O(1)$, where $n$ is the total number of uncensored cases. The BIC approximation to the integrated likelihood implicitly defines that the parameter prior is the unit information prior, which can be viewed as a special case of the Zellner's (fixed) g-prior that contains information approximately equal to that contained in a single observation; see Kass and Wasserman (1995) and Raftery (1995). We denote this parameter prior as $g$-UIP. Our choice of the priors follows Eicher, Papageorgiou, and Raftery (2011) who found that the unit information prior combined with a uniform prior over the model space generally outperformed competing priors.

The model averaging estimator of $\beta$ is given by the posterior mean (PM) defined by

$$
\widehat{\beta}_{D, \mathcal{M}}=\sum_{k=1}^{K} \widehat{\beta}_{D, k} \widehat{\mu}\left(M_{k} \mid D\right) .
$$

The notation $\widehat{\beta}_{D, \mathcal{M}}$ emphasizes the dependence of the estimator on data $D$ and model space $\mathcal{M}$ instead of individual model $M_{k}$. We also compute the corresponding model averaging standard errors as the posterior standard error (PSE) based on the posterior variance of $\theta$

$$
\widehat{V}_{D, \mathcal{M}}^{\beta}=\sum_{k=1}^{K} \widehat{V}_{D, k}^{\beta} \widehat{\mu}\left(M_{k} \mid D\right)+\sum_{k=1}^{K}\left(\widehat{\beta}_{D, k}-\widehat{\beta}_{D, \mathcal{M}}\right)^{2} \widehat{\mu}\left(M_{k} \mid D\right)
$$

where $\widehat{V}_{D, k}^{\beta}$ is the model-specific posterior variance of the partial likelihood estimator. The first term in equation (6) is the average of the posterior variances within models and the second term is the variance of the posterior means across models (i.e. weighted average of the squared deviations of the model-specific from the model averaged estimates) 7

\footnotetext{
${ }^{7}$ Following Volinsky, Madigan. Raftery, and Kronmal (1997) we employ the "leaps and bounds algorithm" to choose top $K$ models.
} 
We conduct inference on each covariate's effect $\beta_{j}$ on the growth spell in the context of BMA using the posterior probability of inclusion (PIP) for each covariate. More precisely, this is the posterior probability that a regression coefficient for a variable is nonzero (posterior effect probability) and is computed as the sum of posterior probabilities of the models which contain that variable. The larger the probability of the nonzero effect, the larger the evidence in favor of the covariate $j$ being part of the true theory 8

While we focus on PIPs for covariates we also report the corresponding posterior tstatistics and interpret them in a "hybrid" sense that views equations (55) and (6) above as a blend of frequentist probability statements about observables given unobservables and a Bayesian probability statement about unobservables given observables. In effect, we report BMA posterior t-statistics for coefficient estimates and interpret them in the classical sense. This kind of approach was proposed by Sala-i Martin. Doppelhofer, and Miller (2004) in the context of growth regressions and argued that the weighting scheme for their "hybrid" model average estimator can be derived as a limiting case of a standard Bayesian analysis as the prior information becomes "dominated by the data. 9

8 Eicher. Henn, and Papageorgiou (2012) following Kass and Raftery (1995) proposed a classification rule to sort the posterior inclusion probability into a categorical measure of the strength of evidence of the covariate's effect: $\mathrm{PIP}<50 \%$ indicates lack of evidence for an effect; $50 \%<\mathrm{PIP}<75 \%$ indicates weak evidence for an effect; $75 \%<\mathrm{PIP}<95 \%$ indicates positive evidence for an effect; $95 \%<\mathrm{PIP}<99 \%$ indicates strong evidence for an effect; $99 \%<\mathrm{PIP}<100 \%$ indicates decisive evidence for an effect. While these chosen cutoffs are not strictly grounded in statistical theory, they, nevertheless provide a good benchmark to use for our analysis.

${ }^{9}$ As noted by Kourtellos. Stylianou, and Tan (2013) the inference based on a BMA posterior t-statistic must be interpreted with caution because its asymptotic distribution is a mixture of Normal distributions, which is often characterized by irregular shapes, far away from Normal, and thereby rendering inference based on classical interpretations invalid. Raftery (1995) provides some guidance on how to interpret posterior tstatistics given various sample sizes. 


\section{$5 \quad$ Empirical Results}

\subsection{Baseline Results}

We apply the BMA methodology to investigate how inequality and redistribution as well as other determinants affect the duration of growth spells. Our baseline estimation is based on a universe of all possible models using 23 covariates from the categories described in Section 3. To control for unobserved heterogeneity and time effects, we always include 3 variables in the model, namely indicator variables for advanced countries, sub-Saharan African countries, and the great moderation. Our priors are based on the assumption that each variable considered has the same probability of being included in the model, namely 0.50 . The first panel of Table 5 presents the results from our baseline estimation. The posterior inclusion probability (PIP) shown in the second column of Table 5 reflects how much the data favors including a particular variable in the regression. The unconditional posterior mean (PME) and standard deviation (PSE) for each determinant (computed taking into account all the possible models), are shown in the third and fourth columns of the Table, respectively. For our purposes, we identify a regressor as a "robust" determinant if its posterior inclusion probability exceeds $75 \%$.

Our results suggest that after controlling for other determinants of growth spells, possible transmission channels, and unobserved heterogeneity, inequality is a robust determinant of growth spells, with a posterior inclusion probability of $97 \%$. In particular, higher inequality adversely affects the duration of growth spells: a unit increase in the Net Inequality coefficient raises the probability that the spell will end the following year by $7.4 \%$. Redistribution, in contrast, enters with a low inclusion probability and, thus, does not seem to affect the 
duration of growth spells, although its general effect appears to be benign 10 Taken together, these results suggest that there is, on average, no trade-off between spell duration and a reduction of inequality through redistribution.

We also identify additional robust determinants for growth spells. We find strong support for some canonical neoclassical growth variables (Solow variables) including initial income and a proxy for human capital accumulation (secondary education), both of which enter with posterior inclusion probability greater than $99 \%$. To the extent that growth spells are part of the (conditional) convergence process, the finding on initial income suggests that as countries get closer to the frontier they start growth spells at higher initial incomes, and these spells are more likely to end suddenly. The marginal impact of these variables is also substantial: on average, a 1,000 US dollar increase of initial income (ppp adjusted, 2000 prices) increases the probability that the spell will end in the next year by $65 \%$, while an additional year in secondary school reduces the risk that the growth spell comes to an end by $75 \%$. Finally, we find some support for a positive role of FDI on spell duration: increasing FDI by $1 \%$ raises the probability that the spell will continue by $3.4 \%$.

Figure 3 is a graphical representation of the importance and sign of the variables in the universe. The plot demonstrates how the estimated coefficients fluctuate for a number of top models shown in the horizontal axis scaled by their posterior model probabilities. Posterior means are shown as positive (blue color), negative (red color), or white to non-inclusion (or a zero coefficient). Variables identified as robust maintain the same sign pretty much throughout the model space.

\footnotetext{
${ }^{10}$ This finding may suggest that a more direct measure of redistribution could be usefully explored. For example, there is evidence that early childhood interventions targeted toward disadvantaged children have substantial impacts on later life outcomes (e.g., Heckman, Pinto, and Savelyev (2000)). Hence, future measures of redistributions could distinguish between societies that engage in redistribution ex-ante via progressive child development and early years programs as opposed to engaging in redistribution ex-post through income taxation or distinguish by type of spending (see Lindert (2004)). Of course, the challenge is to construct such measures with sufficient coverage in order to allow for meaningful estimation.
} 
The remaining columns of Table 5 present coefficient estimates and standard errors from four individual models of the model space. Columns 4-5 present the "full" model, which is the typical model considered in standard analyses because it nests all models since it enjoys the smallest bias (albeit possibly higher variance). It turns out that neither inequality nor redistribution is statistically significant in the "full" model. However, the approximately zero posterior model probability implies that the "full" model is a rather poor model, which can lead to unreliable inference. In contrast, our key BMA results on inequality and redistribution as well as the BMA findings for the other variables are confirmed by the three models with the highest posterior weights (posterior probability) in the model space presented in columns 6-11. Interestingly, their low posterior model probabilities of $0.043,0.039$, and 0.029 suggest that none of the top models is dominant but rather the posterior mass is spread over larger models. Figure 4 confirms these conclusions graphically.

\subsection{Robustness}

We consider further robustness exercises to examine the sensitivity of our baseline results. We begin by looking for nonlinearities in the inequality-redistribution-growth spell relationship. Specifically, we examine whether the growth spell-inequality relationship depends on the extent of inequality, or whether the effect of redistributive policies varies depending on how extensive they are. This is motivated by some preliminary evidence of the existence of possible nonlinearities evident from the unconditional plots in Figure2, as well as theoretical and empirical evidence that the relationship between inequality and growth may be nonlinear discussed in the introduction.

We investigate three separate model averaging specifications, adding sequentially

interaction terms for (i) the bottom 70th and top 30th percentiles for inequality and 
redistribution; (ii) the bottom 70th and top 30th percentiles for inequality only; and (iii) the bottom 70th and top 30th percentiles for redistribution only 11 Overall, results presented in Table 6 suggest that there is no evidence of nonlinearities in any of the three specifications. Therefore, the growth-inequality relationship does not seem to depend on the extent of inequality and that redistributive policies are generally benign irrespective of how extensive they are. In particular, when nonlinear effects for both inequality and redistribution are included (columns 2-4 of Table 6), the coefficients of inequality on growth spell duration when the level of inequality is high (above the 70th percentile) and low (below the 30th percentile) enter with identical inclusion probabilities (93.1\%) and with about the same posterior means (0.18 and 0.14, respectively). There is no evidence of nonlinear effects of redistribution on growth spells as both inclusion probabilities are low. In addition, when nonlinear effects for either inequality or redistribution are included (columns 5-10 of Table 6) we still find no evidence of nonlinear effects in either inequality or redistribution, while inequality still remains robust (when redistribution enters nonlinearly), and redistribution has no effect (when inequality enters nonlinearly). Also, importantly, the conclusions about the variables identified as robust in our baseline specification of Table 5 (namely, secondary education, initial income, and FDI) are preserved. Finally, adding nonlinear effects also identifies the proxy for market distortions (the ratio of price level of investment to price level of consumption) as another potential determinant of growth spells. This is in line with Perotti (1996) and Forbes (2000) and the argument that in a more equitable society taxation on physical capital and human capital will be lower thus the degree of distortions in investment decisions (which promote economic growth) are limited; see Galor (2009) 12

\footnotetext{
${ }^{11}$ Chosen "low/high" cut-offs are selected to address the question of interest-the influence of large values of inequality and redistribution on growth spells - while at the same time allowing enough variation for meaningful estimation in each sample. Alternative percentile cut-offs including bottom 80 and top 20, and bottom 75 and top 25 do not substantially change the conclusions.

${ }^{12} \mathrm{We}$ extend the analysis of linear and generalized linear models to investigate non-linearities in a Cox regression framework. In particular, to detect any patterns of nonlinearity we plot the martingale residuals against inequality and redistribution, as well as investigate partial-residual plots against inequality and
} 
Our next set of robustness investigates alternative and more restrictive model averaging exercises using possible channels of transmission-channels through which inequality or redistribution may affect growth spell duration. First, we define a set of 6 possible channels, namely, human capital (proxied by primary and secondary education), institutions (proxied by democracy and executive constraints), exogenous shocks (proxied by terms of trade, US interest rate, and a large shock to terms of trade), transfer (proxied by government spending and investment spending), conflict and ethnic heterogeneity. Then, we investigate how the importance and magnitude of the effect of inequality (or redistribution) change when each of the channels is (i) excluded from the specification (ii) always included in the specification 13

Starting with the excluded channels, Table 7 shows various specifications where we start from the baseline and exclude, sequentially, variables that proxy each of the identified potential channels from the model space. Overall, the baseline results are preserved in all specifications presented in Table 7 . Inequality still remains a robust determinant of growth spell duration while redistribution has no effect; as in the baseline initial income, secondary education, and FDI are robust determinants. In addition, excluding each of the 6 channels of transmission affects only marginally the inclusion probability and posterior mean of inequality and in, most cases, redistribution. For example, consistent with the notion that human capital and institutions are negatively correlated with inequality excluding human capital or institutions from the baseline (Table 7, columns 2-3, and 5-6, respectively) increases the importance of inequality by only about $3 \%$ (and the posterior mean by about

redistribution. We repeat this for all models presented in Table 5, namely the best model according to BMA (that is, the model that includes regressors with PIP $\geq 75 \%$ ), the full model, and the top 3 models. In all these models we find no significant evidence of non-linearity inequality and redistribution.

${ }^{13}$ For example, if institutions is a channel through which inequality affects the duration of growth spells, then the coefficient (and inclusion probability) of inequality should be different (larger, if we assume that inequality and institutions are negatively correlated) if institutions is excluded from the specification (compared to the specification when both inequality and institutions are included). Similarly, if the institutions channel is always included in the model space, the coefficient and inclusion probability of inequality should be different (compared to the case where institutions was free to vary across models). 
$0.5 \%)$. The effect is larger on redistribution but its inclusion probability still remains low, so it is still not a robust determinant. Similarly, excluding distortions or ethnic heterogeneity from the baseline (both of which are positively correlated with inequality) lowers inclusion probabilities of inequality by $4 \%$ and $8 \%$ (Table 7 , columns $14-15$, and 20-21, respectively). Excluding the conflict or transfer channels from the baseline has virtually no effect on the inclusion probabilities or the estimated means for inequality.

For the next set of robustness checks we always include (sequentially) each of the 6 channels in every model in the model space, while the rest of the regressors are allowed to vary across models. Each specification in Table 8 shows the channel that is always included on the top. As in the previous robustness exercise, we find that our baseline results are confirmed. In all specifications, inequality is a robust determinant of growth spells with its inclusion probabilities and posterior means changing only marginally; redistribution still does not affect growth spells.

\section{Conclusion}

This paper uses a model averaging methodology for duration models to investigate the relationship between inequality, redistribution, and the duration of growth spells. To ensure a comprehensive search, our analysis accounts for a rich set of possible determinants of growth spells including neoclassical growth, exogenous shocks, human capital, institutions, macroeconomic, and sociopolitical factors, and also controls for unobserved heterogeneity and time effects.

Once model uncertainty is accounted for, the results from our investigation based on a broad number of determinants can be summarized as follows. First, we find strong evidence that lower inequality is strongly and robustly correlated with longer growth spells, 
while redistribution does not influence the duration of growth spells-although its effect is generally benign. This suggests that the inequality-growth relationship is not due to the impact of inequality on redistribution, and that the combined direct and indirect effects of redistribution-including the effects of the resulting lower inequality-are on average spellpreserving. In addition, we find no evidence of nonlinearities in the inequality-redistributiongrowth spell relationship. Therefore, the effect of inequality on growth spell duration does not depend on the extent of inequality while redistributive policies, irrespective of their magnitude, are generally benign for growth spells. We also identify a handful of additional economic characteristics that influence growth spells lower initial income, higher secondary education and higher FDI are associated with longer spell duration.

Further work is needed to examine how inequality and redistribution and the robust characteristics operate, how they are differentiated, and how they interact. Channels of transmission of inequality and redistribution to growth spells also need to be further explored. But the conclusions from our analysis already have some useful policy implications. For example, the fact that we find no evidence for Okun's big trade-off hypothesis suggests that more redistribution, irrespective of its magnitude, and the resulting reduction in inequality, are associated with higher and more durable growth. More broadly, our findings suggest that policy analysis and recommendations should not be based on one specification which may result in fragile conclusions. Properly accounting for model uncertainty is important for policy makers seeking to use findings of growth empirics to offer policy advice.

\section{References}

Acemoglu, D., and A. Johnson, 2005, Unbundling Institutions, Journal of Political Economy 113, 949-995. 
Acemoglu, Daron, R. Johnson, Simon, James Robinson, and Yunyong Thaicharoen, 2003, Institutional causes, macroeconomic symptoms: volatility, crises and growth, Journal of Monetary Economics 50, 49-123.

Afonso, A., and D. Furceri, 1997, Government Size, Composition, Volatility and Economic Growth, European Journal of Political Economy 26, 517-532.

Aizenman, J., and M. Spiegel, 2010, Takeoffs, Review of Development Economics 14, 117 196.

Alesina, A., R. Baqir, and W. Easterly, 1999, Public goods and ethnic divisions, Quarterly Journal of Economics 114, 1243-1284.

Alesina, A., A. Devleeschauwer, W. Easterly, S. Kurlat, and R. Wacziarg, 2003, Fractionalization, Journal of Economic Growth 8, 155-194.

Alesina, A., and R. Perotti, 1996, Income Distribution, Political Instability and Investment, European Economic Review 40, 1203-1228.

Alesina, A., and D. Rodrik, 1994, Distributive Politics and Economic Growth, Quarterly Journal of Economics 109, 465-490.

Antoshin, S., A. Berg, and M. Souto, 2008, Testing for Structural Breaks in Small Samples, Working Paper No. 75 (Washington: International Monetary Fund).

Bai, J., and P. Perron, 1998, Estimating and Testing Linear Models with Multiple Structural Change, Econometrica 66, 47-78.

Banerjee, A. V., and E. Duflo, 2003, Inequality and Growth: What Can the Data Say?, Journal of Economic Growth 8, 267-299. 
Barro, R., 2000, Inequality and Growth in a Panel of Countries, Journal of Economic Growth $5,5-32$.

Berg, A., J. Ostry, and J. Zettelmeyer, 2012, What Makes the Growth Sustained?, Journal of Development Economics 81, 149-166.

Boadway, R., and M. Keen, 2000, Redistribution, in A.B. Atkinson, and F. Bourguignon, ed.: Handbook of Income Distribution . pp. 677-789 (Elsevier: Amsterdam).

Brock, W., and S. D. Durlauf, 2001, Growth Empirics and Reality, World Bank Economic Review 15, 229-272.

Brückner, M., K. Gerling, and H. P. Grüner, 2010, Wealth Inequality and Credit Markets: Evidence from Three Industrialized Countries, Journal of Economic Growth 15, 155-176.

Collier, P., and D. Rohner, 2010, Democracy, Development, and Conflict, Journal of the European Economic Association 6, 531-540.

Durlauf, S. N., A. Kourtellos, and C. M. Tan, 2008, Are Any Growth Theories Robust?, Economic Journal 118, 329-346.

Eicher, T., C. Henn, and C. Papageorgiou, 2012, Trade Creation and Diversion Revisited: Accounting for Model Uncertainty and Natural Trading Partner Effects, Journal of Applied Econometrics 27, 296-321.

Eicher, T., C. Papageorgiou, and A. E. Raftery, 2011, Default Priors And Predictive Performance In Bayesian Model Averaging, With Application To Growth Determinants, Journal of Applied Econometrics 26, 30-55.

Fernandez, C., E. Ley, and M. Steel, 2001, Model Uncertainty in Cross-Country Growth Regressions, Journal of Applied Econometrics 16, 563-576. 
Forbes, K. J., 2000, A Reassessment of the Relationship between Inequality and Growth, American Economic Review 90, 869-87.

Galor, O., 2009, Inequality and Economic Development: An Overview, Department of Economics, Brown University, mimeo.

— , and O. Moav, 2004, From Physical to Human Capital Accumulation: Inequality and the Process of Development, Review of Economic Studies 71, 1001-1026.

Galor, O., and J. Zeira, 1993, Income Distribution and Macroeconomics, Review of Economic Studies 60, 35-52.

Halter, D., M. Oechslin, and J. Zweimüller, 2014, Inequality and Growth: The Neglected Time Dimension, Journal of Economic Growth 19, 81-104.

Hausmann, R., L. Prichett, and D. Rodrik, 2005, Growth Accelerations, Journal of Economic Growth 10, 303-329.

Hausmann, R., F. Rodriquez, and R. Wagner, 2006, Growth Collapses, Working Paper No. 136, Center for International Development.

Heckman, J., R. Pinto, and P. Savelyev, 2000, Understanding the Mechanisms through Which an Influential Early Childhood Program Boosted Adult Outcomes, American Economic Review 103, 2052-86.

Jerzmanowski, M., 2006, Empirics of Hills, Plateaus, Mountains and Plains: a Markovswitching Approach to Growth, Journal of Development Economics 81, 357-385.

Jones, B. F., and B. A. Olken, 2008, The Anatomy of Start-Stop Growth, Review of Economics and Statistics 90, 582-587.

Kaldor, N., 1967, A Model of Economic Growth, The Economic Journal 67, 591-624. 
Kass, R., and L. Wasserman, 1995, A Reference Bayesian Rest for Nested Hypotheses and its Relationship to the Schwarz Criterion, Journal of the American Statistical Association 90, 928-934.

Kass, R. E., and A. E. Raftery, 1995, Bayes Factors, Journal of the American Statistical Association 90, 773-795.

Kerekes, M., 2011, Analyzing the Patterns of Economic Growth: a Production Possibility Frontier Approach, Working Paper, Freie Universitat Berlin.

Kourtellos, A., I. Stylianou, and C. M. Tan, 2013, Failure to Launch? The Role of Land Inequality in Transition Delays, European Economic Review 62, 98-113.

Lane, P. R., and G. M. Milesi-Ferretti, 2002, Long-Term Capital Movements, in B. S. Bernanke, and K. Rogoff, ed.: NBER Macroeconomics Annual 2001, Volume 16 (National Bureau of Economic Research, Inc.).

Lindert, P.H., 2004, Growing Public: Social Spending and Economic Growth Since the Eighteenth Century (Cambridge University Press: UK).

Malik, A., and J. R. W. Temple, 2009, The Geography of Output Volatility, Journal of Development Economics 90, 163-178.

Mankiw, N. G., D. Romer, and D. Weil, 1992, A Contribution to the Empirics of Economic Growth, Quarterly Journal of Economics CVII, 407-437.

Meltzer, A., and S. Richard, 1981, A Rational Theory of the Size of Government, Journal of Political Economy 89, 914-27.

Milanovic, B., 2000, The Median Voter Hypothesis, Income Inequality, and Income Redistribution: An Empirical Test with the Required Data, European Journal of Political Economy 16, 367-410. 
Mirestean, A., and C. Tsangarides, 2015, Model Uncertainty and Endogeneity in Growth Empirics, Journal of Applied Econometrics (forthcoming).

Okun, A.M., 1975, Equality and Efficiency: the Big Trade-Off (Brookings Institution Press: Washington).

Ostry, J. D., A. Berg, and C. G. Tsangarides, 2014, Redistribution, Inequality, and Growth, IMF Discussion Note, SDN/14/02.

Panizza, U., 2002, Income Inequality and Economic Growth: Evidence from American Data, Journal of Economic Growth 7, 25-41.

Perotti, R., 1996, Growth, Income Distribution, and Democracy: What the Data Say, Journal of Economic Growth 1, 149-87.

Persson, T., and G. Tabellini, 1994, Is Inequality Harmful for Growth?, The American Economic Review 84, 600-621.

— , 1996, Federal Fiscal Constitutions: Risk Sharing and Redistribution, Journal of Political Economy 104, 9791009.

Piketty, T., 2014, Capital in the Twenty-First Century (The Belknap Press of Harvard University Press: Cambridge Massachusetts).

Pritchett, L., 2000, Understanding Patterns of Economic Growth: Searching for Hills Among Plateaus, Mountains, and Plains, World Bank Economic Review 90, 221-250.

Raftery, A. E., 1995, Bayesian Model Selection in Social Research (with Discussion), Sociological Methodology 25, 111-196.

Rajan, R. G., 2010, Fault Lines: How Hidden Fractures Still Threaten the World Economy (Princeton University Press: Princeton, USA). 
Rodrik, Dani, 1999, Where did all the growth go? External shocks, social conflict, and growth collapses, Journal of Economic Growth 4, 385-412.

Romer, C. D., and D. H. Romer, 2010, The Macroeconomic Effects of Tax Changes: Estimates Based on a New Measure of Fiscal Shocks, American Economic Review 100, 763-801.

Sachs, J., J. L. Gallup, and A. Mellinger, 1999, Geography and Economic Development, International Regional Science Review 22, 172-232.

Saez, E., 2015, Striking it Richer: The Evolution of Top Incomes in the United States, Department of Economics, University of Berkley, mimeo.

Saint-Paul, G., and T. Verdier, 1996, Inequality, redistribution and growth: A challenge to the conventional political economy approach, European Economic Review 40, 719-728.

Sala-i Martin, X., G. Doppelhofer, and R. Miller, 2004, Determinants of Long-term Growth: a Bayesian Averaging of Classical Estimates (BACE) Approach, American Economic Review 94, 813-835.

Solt, F., 2009, Standardizing the World Income Inequality Database, Social Science Quarterly 90, 231-42.

Stiglitz, J., 2013, The Price of Inequality: How Today's Divided Society Endangers Our Future (W. W. Norton \& Company: New York).

Tanzi, V., and L. Zee, 1997, Fiscal Policy and Long-Run Growth, Journal of Political Economy 44, 179-209.

Tsangarides, C. G., 2012, Determinants of Growth Spells: is Africa Different?, Working Paper No. 12/227 (Washington: International Monetary Fund). 
Volinsky, C., D. Madigan, A. Raftery, and R. Kronmal, 1997, Bayesian Model Averaging in Proportional Hazards Model: Predicting the Risk of a Stroke, Applied Statistics 46, $443-448$. 
Figure 1: Hills, Cliffs, Mountains, and Plateaus

We present the real GDP per capita for eight countries for the period 1960-2010. The dashed line denotes upbreaks and the dotted line downbreaks

(a) US

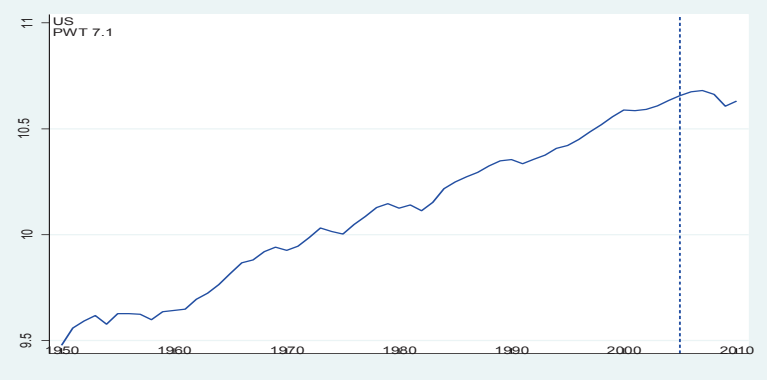

(c) Haiti

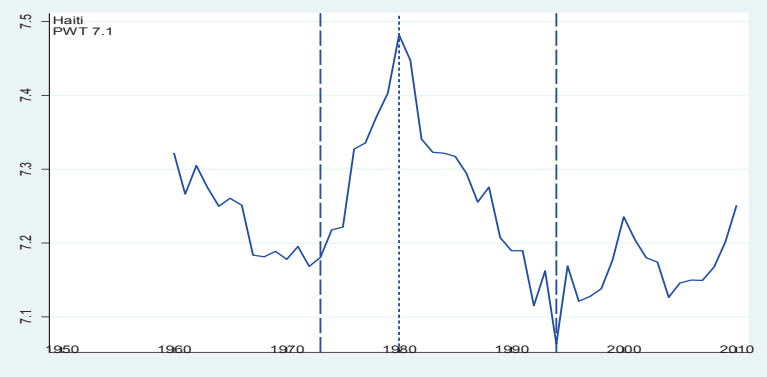

(e) China

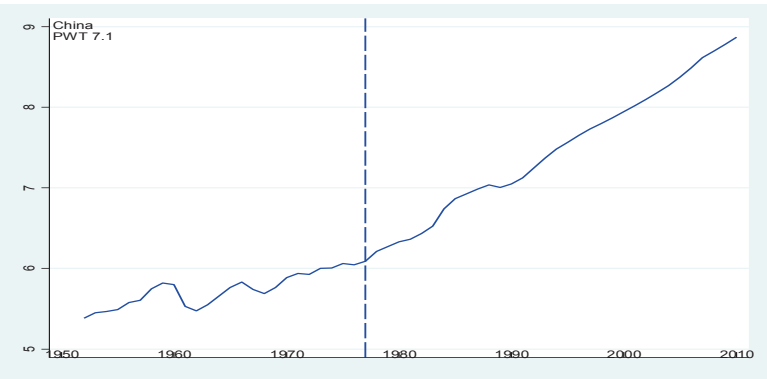

(h) Jordan

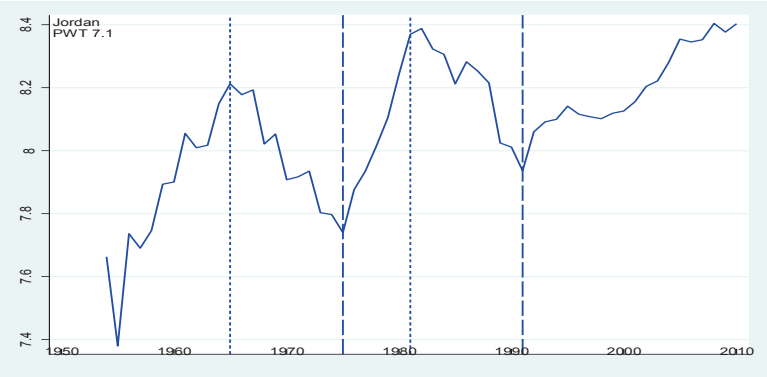

(b) Canada

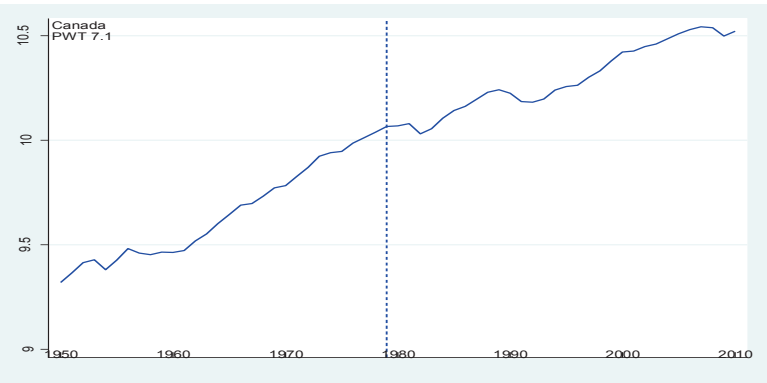

(d) Chile

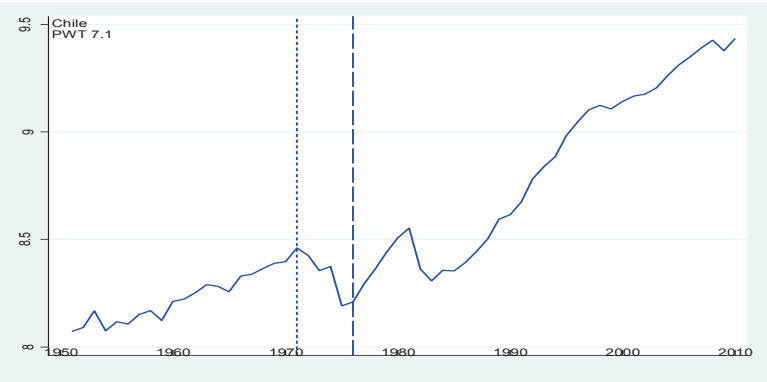

(f) Korea

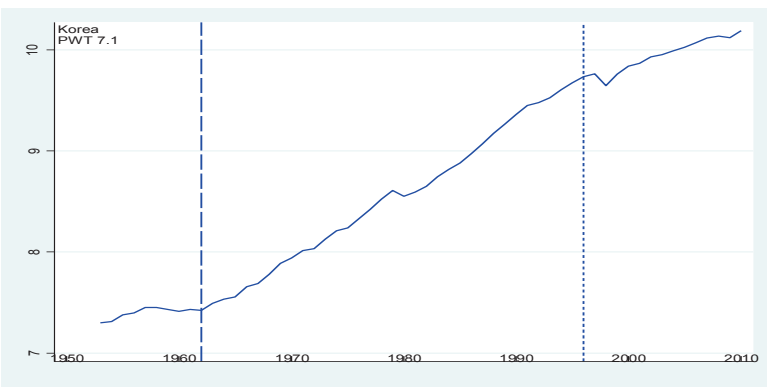

(h) Egypt

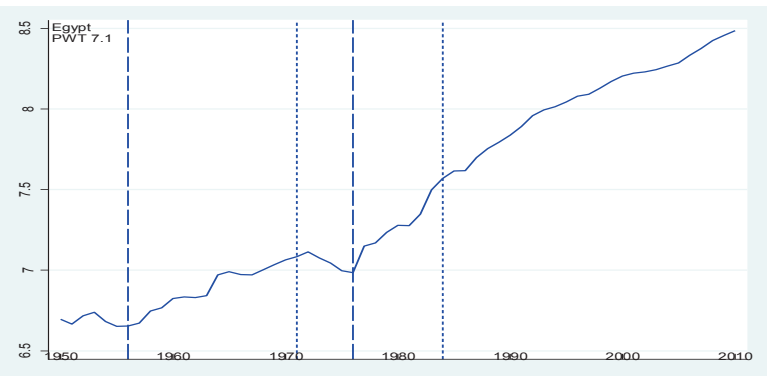


Figure 2: Spell duration, inequality, and redistribution

This figure presents unconditional joint distribution of spell duration, inequality, and redistribution.
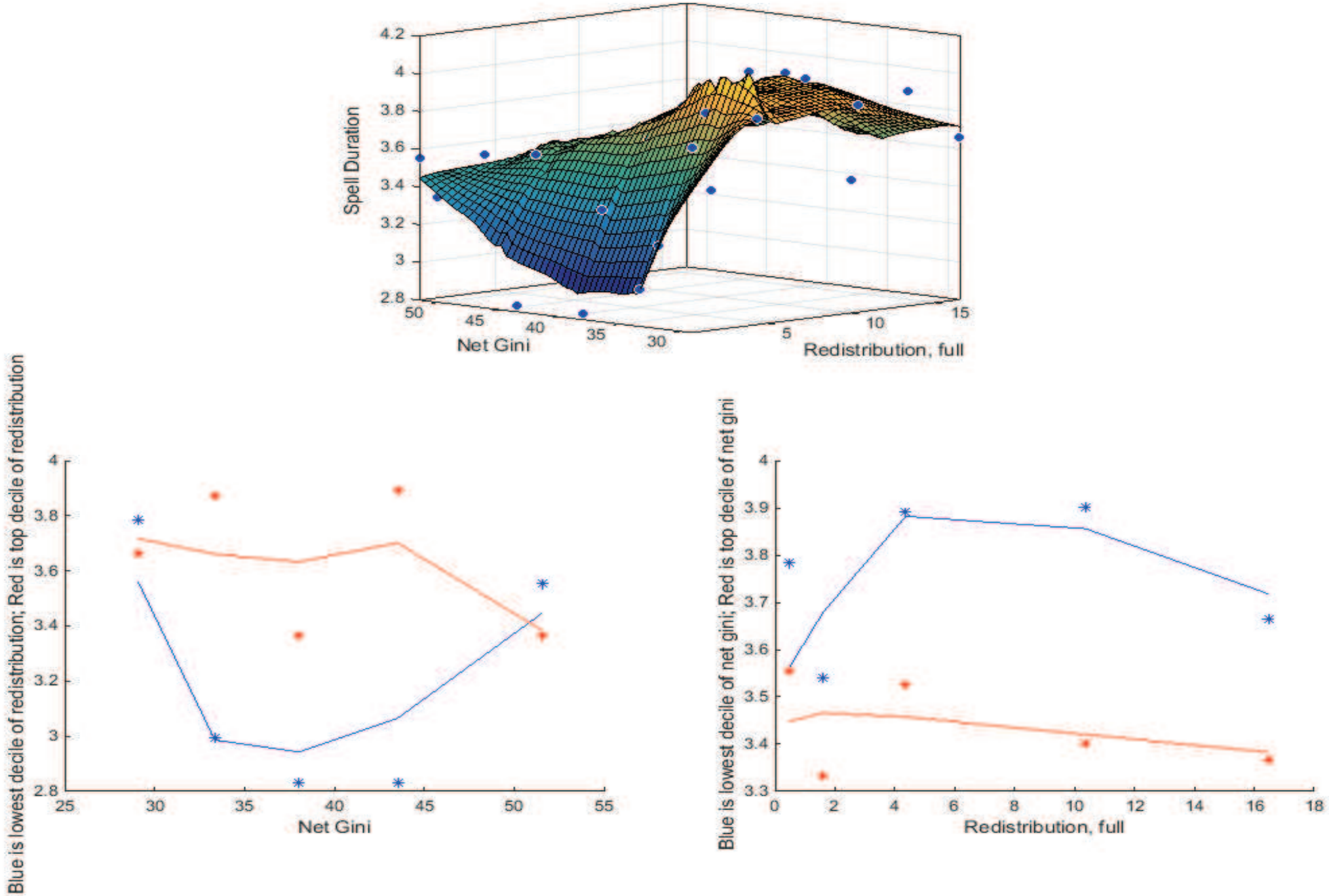
Figure 3: Regressors Included in Best Models - Growth Spells

The blue color corresponds to a positive coefficient, red to a negative coefficient, and white to non-inclusion (a zero coefficient). On the horizontal axis it shows the best models, scaled by their PMPs. The time and regional dummies are always kept in the model.

Models selected by BMA

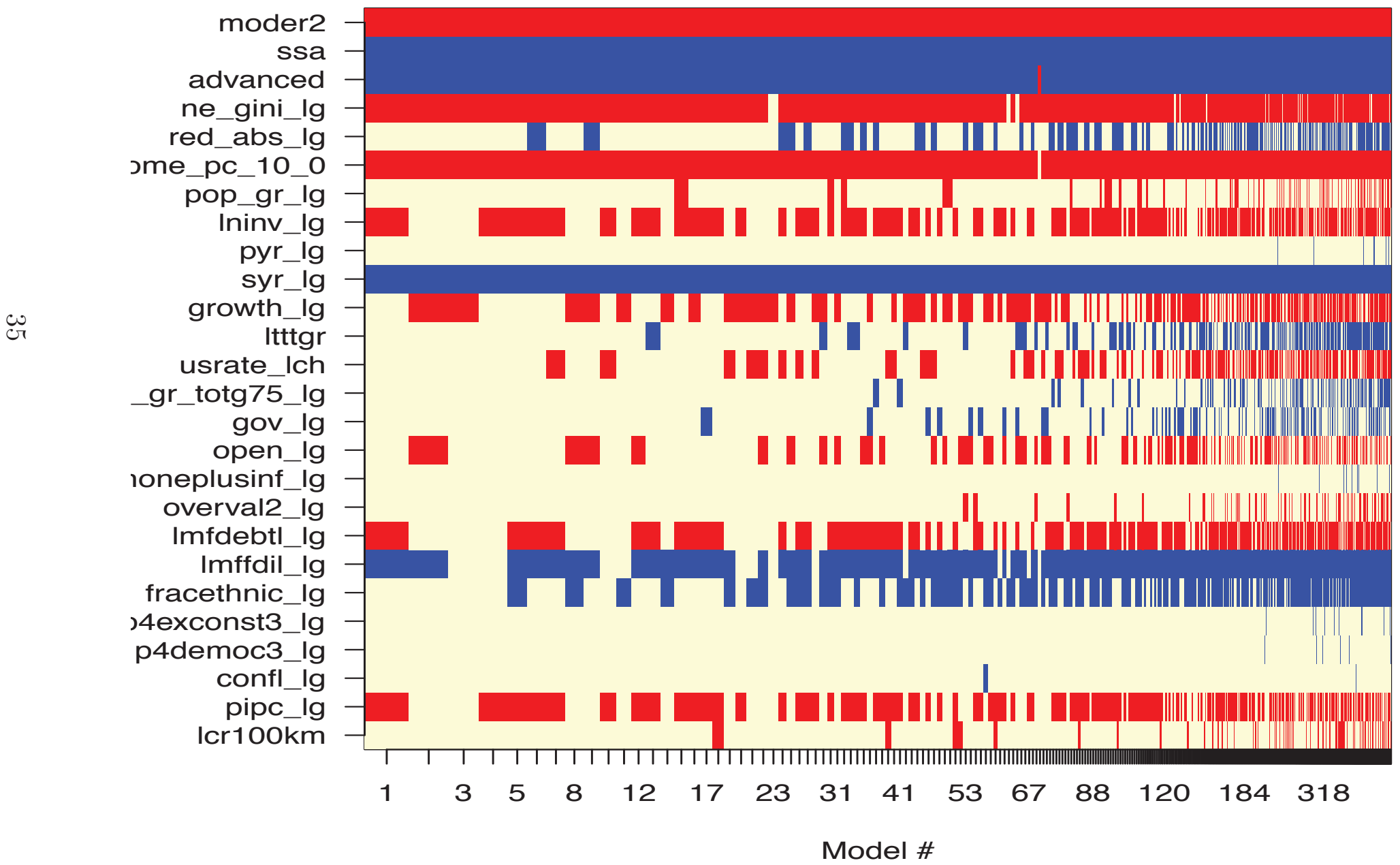




\section{Figure 4: Model Size Distribution and Posterior Model Probabilities}

The red line denotes the prior model size distribution while the blue line denotes the posterior model size distribution.

Posterior Model Size Distribution Mean: 14.95625

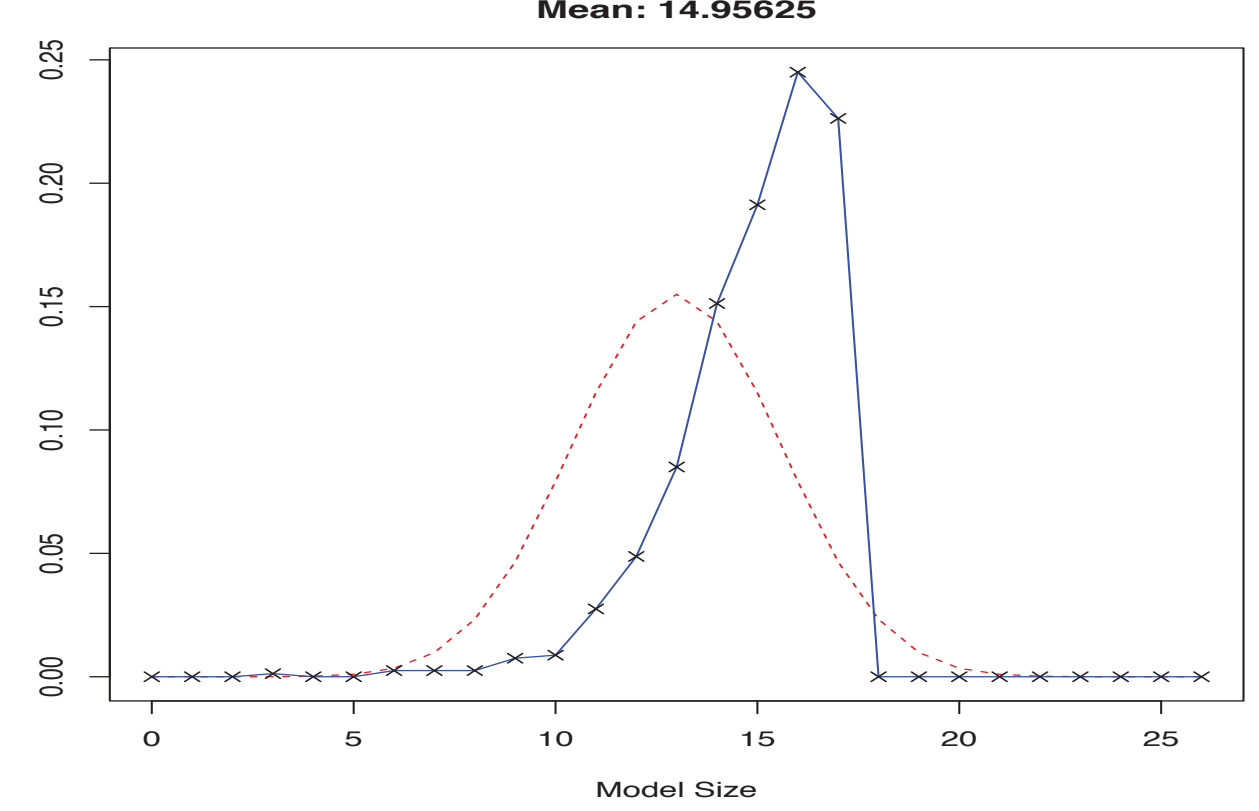


Table 1: Growth Breaks by Decade and Country Group

\begin{tabular}{|c|c|c|c|c|c|c|c|c|c|c|c|c|c|}
\hline \multirow[b]{2}{*}{ Region } & \multirow[b]{2}{*}{$\begin{array}{r}\text { Number of } \\
\text { countries }\end{array}$} & \multicolumn{6}{|c|}{$\mathbf{h}=\mathbf{5}$} & \multicolumn{6}{|c|}{$h=8$} \\
\hline & & Total & $\begin{array}{r}\text { Average } \\
\text { break size }\end{array}$ & $50 \mathrm{~s}-60 \mathrm{~s}$ & $70 \mathrm{~s}$ & $80 \mathrm{~s}$ & $90-00 \mathrm{~s}$ & Total & $\begin{array}{r}\text { Average } \\
\text { break size }\end{array}$ & $50 \mathrm{~s}-60 \mathrm{~s}$ & $70 \mathrm{~s}$ & $80 \mathrm{~s}$ & $90-00 \mathrm{~s}$ \\
\hline Total upbreaks & 153 & 157 & 7.5 & 33 & 31 & 39 & 54 & 106 & 6.2 & 17 & 16 & 29 & 44 \\
\hline Advanced & 29 & 13 & 3.9 & 6 & 1 & 4 & 2 & 9 & 3.8 & 6 & 0 & 2 & 1 \\
\hline Asia & 25 & 33 & 6.5 & 7 & 8 & 7 & 11 & 31 & 5.3 & 5 & 7 & 8 & 11 \\
\hline LA and Caribbean & 33 & 46 & 6.5 & 11 & 9 & 11 & 15 & 23 & 4.9 & 4 & 3 & 6 & 10 \\
\hline Africa & 46 & 48 & 10.0 & 5 & 11 & 11 & 21 & 30 & 8.9 & 1 & 4 & 7 & 18 \\
\hline Middle East & 20 & 17 & 8.3 & 4 & 2 & 6 & 5 & 13 & 7.6 & 1 & 2 & 6 & 4 \\
\hline Total downbreaks & 153 & 164 & -7.2 & 20 & 65 & 41 & 38 & 111 & -6.1 & 10 & 50 & 28 & 23 \\
\hline Advanced & 35 & 29 & -3.4 & 1 & 14 & 4 & 10 & 23 & -3.7 & 1 & 12 & 1 & 9 \\
\hline Asia & 25 & 21 & -9.2 & 1 & 9 & 5 & 6 & 14 & -6.1 & 1 & 6 & 3 & 4 \\
\hline LA and Caribbean & 19 & 47 & -6.7 & 7 & 14 & 15 & 11 & 26 & -5.4 & 1 & 10 & 9 & 6 \\
\hline Africa & 59 & 49 & -8.8 & 8 & 21 & 11 & 9 & 32 & -7.1 & 4 & 15 & 11 & 2 \\
\hline Middle East & 15 & 18 & -9.5 & 3 & 7 & 6 & 2 & 16 & -9.1 & 3 & 7 & 4 & 2 \\
\hline
\end{tabular}


Table 2: Frequency and Duration of Growth Spells

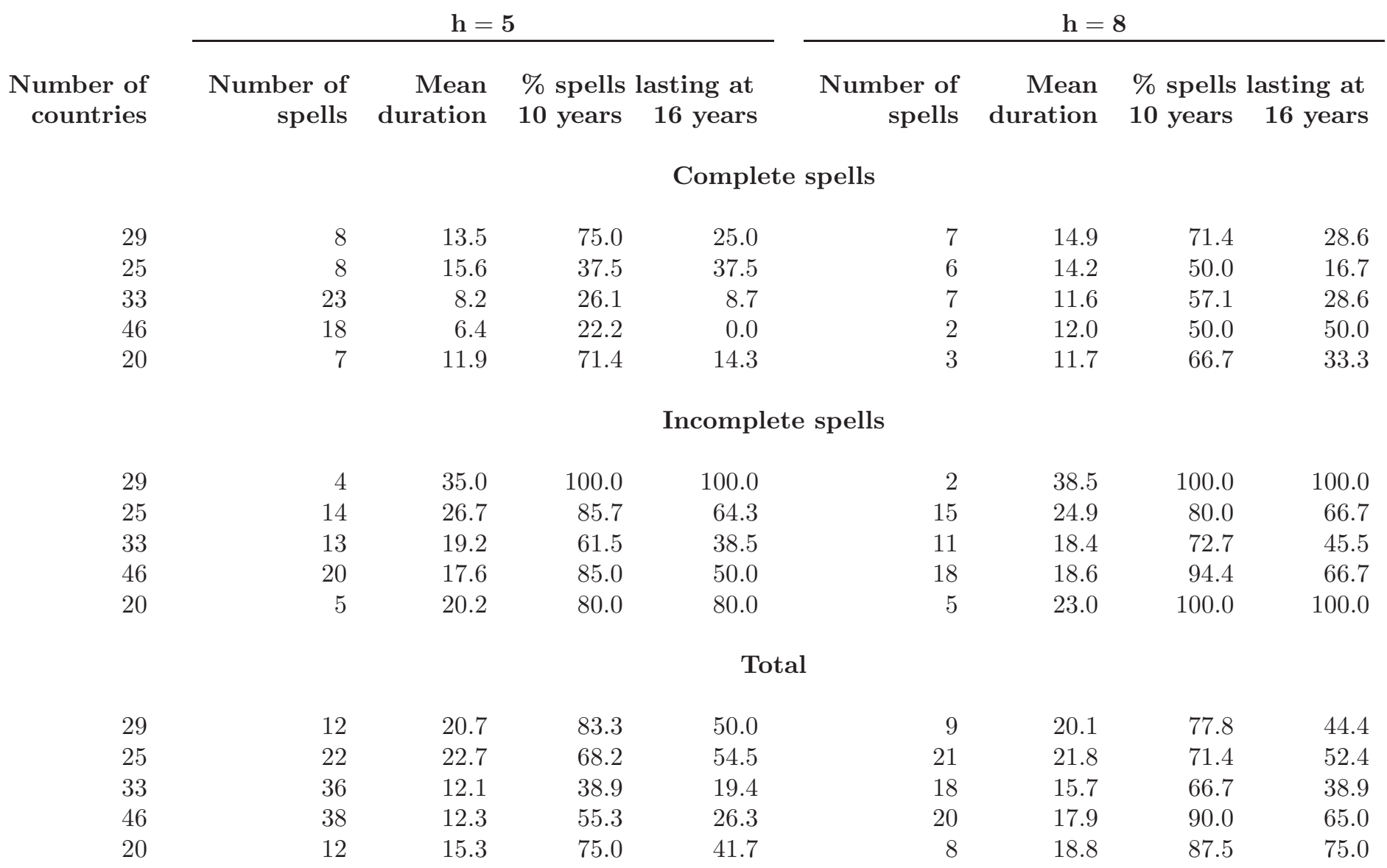


Table 3: Average Growth Before, During and After Growth Spells

\begin{tabular}{|c|c|c|c|c|c|c|c|c|c|c|}
\hline & \multicolumn{5}{|c|}{$\mathrm{h}=\mathbf{5}$} & \multicolumn{5}{|c|}{$\mathrm{h}=8$} \\
\hline & \multicolumn{3}{|c|}{ Average growth } & \multicolumn{2}{|c|}{3 years ... } & \multicolumn{3}{|c|}{ Average growth } & \multicolumn{2}{|c|}{3 years ... } \\
\hline & before & during & after & $\begin{array}{r}\text { before } \\
\text { start }\end{array}$ & $\begin{array}{r}\text { after } \\
\text { end }\end{array}$ & before & during & after & $\begin{array}{r}\text { before } \\
\text { start }\end{array}$ & $\begin{array}{r}\text { after } \\
\text { end }\end{array}$ \\
\hline & \multicolumn{10}{|c|}{ Complete spells } \\
\hline Advanced & 3.1 & 5.2 & 0.7 & 2.6 & 0.4 & 3.2 & 5.5 & 0.7 & 2.4 & 1.7 \\
\hline Asia & -1.0 & 6.7 & -3.9 & -0.8 & -0.8 & 0.4 & 5.7 & 0.9 & 0.7 & 0.8 \\
\hline LA and Caribbean & -0.8 & 5.5 & -1.5 & -1.2 & -1.9 & 0.3 & 4.7 & -1.3 & 0.3 & -1.8 \\
\hline Africa & -1.3 & 8.9 & -2.4 & -2.2 & -2.6 & -0.3 & 4.7 & -3.7 & -2.6 & -4.4 \\
\hline \multirow[t]{2}{*}{ Middle East } & -2.3 & 4.5 & -2.5 & -3.6 & -2.9 & -2.2 & 5.7 & -1.2 & -0.1 & -0.2 \\
\hline & \multicolumn{10}{|c|}{ Incomplete spells } \\
\hline Advanced & 1.2 & 5.6 & - & 0.4 & - & 1.7 & 6.7 & - & 0.3 & - \\
\hline Asia & -1.7 & 5.0 & - & -3.4 & - & -1.5 & 4.7 & - & -3.9 & - \\
\hline LA and Caribbean & -2.0 & 4.8 & - & -2.3 & - & -0.8 & 4.3 & - & -2.3 & - \\
\hline Africa & -4.6 & 4.8 & - & -5.9 & - & -3.6 & 6.3 & - & -5.4 & - \\
\hline Middle East & -2.6 & 3.8 & - & -4.6 & - & -3.7 & 3.8 & - & -6.2 & - \\
\hline
\end{tabular}

\begin{tabular}{|c|c|c|c|c|c|c|c|c|c|c|}
\hline & \multicolumn{5}{|c|}{$\mathrm{h}=\mathbf{5}$} & \multicolumn{5}{|c|}{$\mathrm{h}=8$} \\
\hline & \multicolumn{3}{|c|}{ Average growth } & \multicolumn{2}{|c|}{3 years ... } & \multicolumn{3}{|c|}{ Average growth } & \multicolumn{2}{|c|}{3 years ... } \\
\hline & before & during & after & $\begin{array}{r}\text { before } \\
\text { start }\end{array}$ & $\begin{array}{r}\text { after } \\
\text { end }\end{array}$ & before & during & after & $\begin{array}{r}\text { before } \\
\text { start }\end{array}$ & $\begin{array}{r}\text { after } \\
\text { end }\end{array}$ \\
\hline & \multicolumn{10}{|c|}{ Complete spells } \\
\hline Advanced & 3.1 & 5.2 & 0.7 & 2.6 & 0.4 & 3.2 & 5.5 & 0.7 & 2.4 & 1.7 \\
\hline Asia & -1.0 & 6.7 & -3.9 & -0.8 & -0.8 & 0.4 & 5.7 & 0.9 & 0.7 & 0.8 \\
\hline LA and Caribbean & -0.8 & 5.5 & -1.5 & -1.2 & -1.9 & 0.3 & 4.7 & -1.3 & 0.3 & -1.8 \\
\hline Africa & -1.3 & 8.9 & -2.4 & -2.2 & -2.6 & -0.3 & 4.7 & -3.7 & -2.6 & -4.4 \\
\hline \multirow[t]{2}{*}{ Middle East } & -2.3 & 4.5 & -2.5 & -3.6 & -2.9 & -2.2 & 5.7 & -1.2 & -0.1 & -0.2 \\
\hline & \multicolumn{10}{|c|}{ Incomplete spells } \\
\hline Advanced & 1.2 & 5.6 & - & 0.4 & - & 1.7 & 6.7 & - & 0.3 & - \\
\hline Asia & -1.7 & 5.0 & - & -3.4 & - & -1.5 & 4.7 & - & -3.9 & - \\
\hline LA and Caribbean & -2.0 & 4.8 & - & -2.3 & - & -0.8 & 4.3 & - & -2.3 & - \\
\hline Africa & -4.6 & 4.8 & - & -5.9 & - & -3.6 & 6.3 & - & -5.4 & - \\
\hline Middle East & -2.6 & 3.8 & - & -4.6 & - & -3.7 & 3.8 & - & -6.2 & - \\
\hline
\end{tabular}

\begin{tabular}{|c|c|c|c|c|c|c|c|c|c|c|}
\hline & \multicolumn{5}{|c|}{$\mathrm{h}=\mathbf{5}$} & \multicolumn{5}{|c|}{$\mathrm{h}=8$} \\
\hline & \multicolumn{3}{|c|}{ Average growth } & \multicolumn{2}{|c|}{3 years ... } & \multicolumn{3}{|c|}{ Average growth } & \multicolumn{2}{|c|}{3 years ... } \\
\hline & before & during & after & $\begin{array}{r}\text { before } \\
\text { start }\end{array}$ & $\begin{array}{r}\text { after } \\
\text { end }\end{array}$ & before & during & after & $\begin{array}{r}\text { before } \\
\text { start }\end{array}$ & $\begin{array}{r}\text { after } \\
\text { end }\end{array}$ \\
\hline & \multicolumn{10}{|c|}{ Complete spells } \\
\hline Advanced & 3.1 & 5.2 & 0.7 & 2.6 & 0.4 & 3.2 & 5.5 & 0.7 & 2.4 & 1.7 \\
\hline Asia & -1.0 & 6.7 & -3.9 & -0.8 & -0.8 & 0.4 & 5.7 & 0.9 & 0.7 & 0.8 \\
\hline LA and Caribbean & -0.8 & 5.5 & -1.5 & -1.2 & -1.9 & 0.3 & 4.7 & -1.3 & 0.3 & -1.8 \\
\hline Africa & -1.3 & 8.9 & -2.4 & -2.2 & -2.6 & -0.3 & 4.7 & -3.7 & -2.6 & -4.4 \\
\hline \multirow[t]{2}{*}{ Middle East } & -2.3 & 4.5 & -2.5 & -3.6 & -2.9 & -2.2 & 5.7 & -1.2 & -0.1 & -0.2 \\
\hline & \multicolumn{10}{|c|}{ Incomplete spells } \\
\hline Advanced & 1.2 & 5.6 & - & 0.4 & - & 1.7 & 6.7 & - & 0.3 & - \\
\hline Asia & -1.7 & 5.0 & - & -3.4 & - & -1.5 & 4.7 & - & -3.9 & - \\
\hline LA and Caribbean & -2.0 & 4.8 & - & -2.3 & - & -0.8 & 4.3 & - & -2.3 & - \\
\hline Africa & -4.6 & 4.8 & - & -5.9 & - & -3.6 & 6.3 & - & -5.4 & - \\
\hline Middle East & -2.6 & 3.8 & - & -4.6 & - & -3.7 & 3.8 & - & -6.2 & - \\
\hline
\end{tabular}


Table 4: Average Growth, Inequality, and Redistribution: Before, During and After Growth Spells

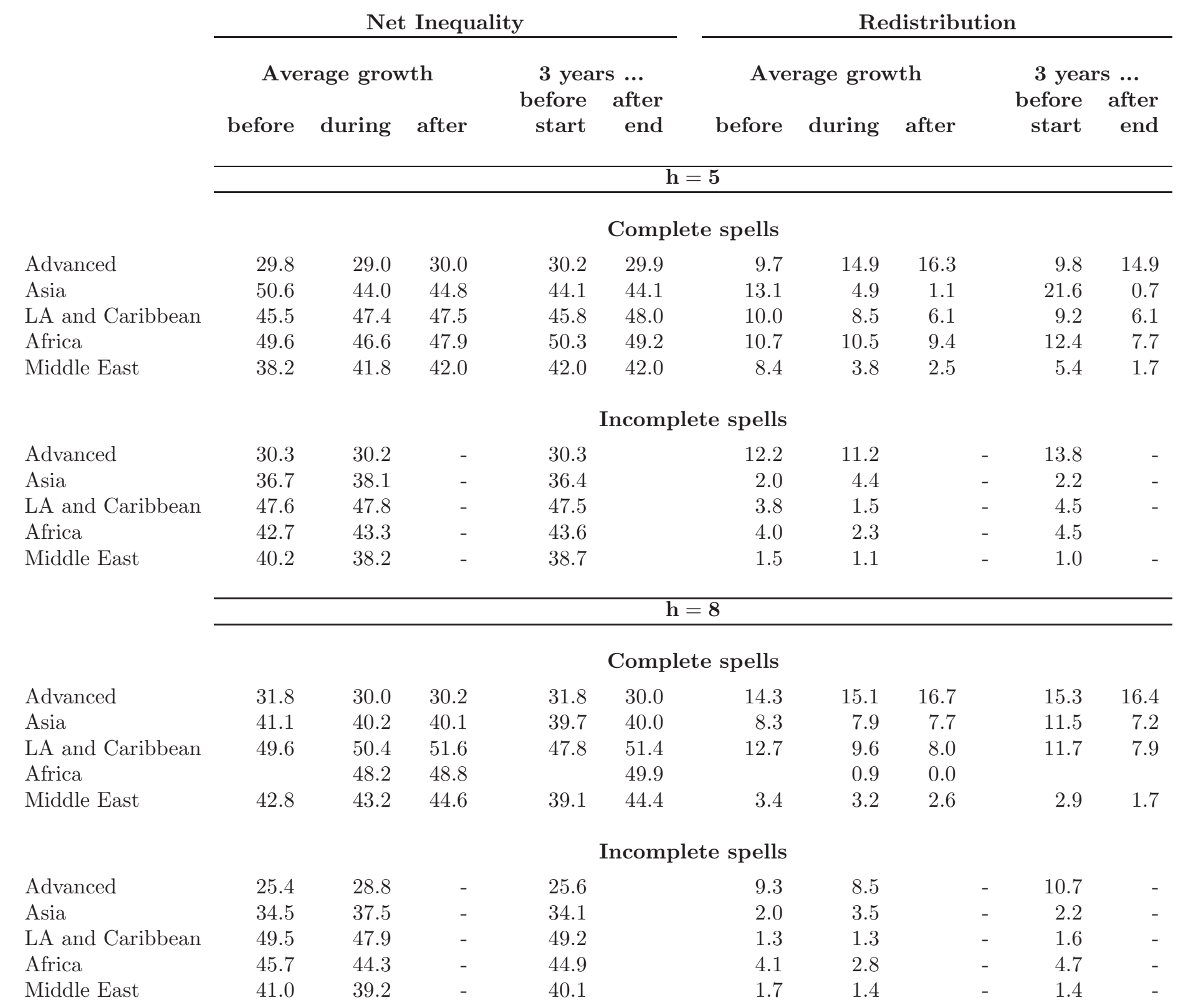

\begin{tabular}{|c|c|c|c|c|c|c|c|c|c|c|c|}
\hline & \multicolumn{5}{|c|}{ Net Inequality } & \multicolumn{6}{|c|}{ Redistribution } \\
\hline & \multicolumn{3}{|c|}{ Average growth } & \multirow{2}{*}{\multicolumn{2}{|c|}{$\begin{array}{c}3 \text { years ... } \\
\text { before after } \\
\text { start } \quad \text { end }\end{array}$}} & \multicolumn{3}{|c|}{ Average growth } & \multicolumn{3}{|c|}{3 years ... } \\
\hline & before & during & after & & & before & during & after & & $\begin{array}{r}\text { before } \\
\text { start }\end{array}$ & $\begin{array}{r}\text { after } \\
\text { end }\end{array}$ \\
\hline & \multicolumn{11}{|c|}{$\mathrm{h}=\mathbf{5}$} \\
\hline & \multicolumn{11}{|c|}{ Complete spells } \\
\hline Advanced & 29.8 & 29.0 & 30.0 & 30.2 & 29.9 & 9.7 & 14.9 & 16.3 & & 9.8 & 14.9 \\
\hline Asia & 50.6 & 44.0 & 44.8 & 44.1 & 44.1 & 13.1 & 4.9 & 1.1 & & 21.6 & 0.7 \\
\hline LA and Caribbean & 45.5 & 47.4 & 47.5 & 45.8 & 48.0 & 10.0 & 8.5 & 6.1 & & 9.2 & 6.1 \\
\hline Africa & 49.6 & 46.6 & 47.9 & 50.3 & 49.2 & 10.7 & 10.5 & 9.4 & & 12.4 & 7.7 \\
\hline \multirow[t]{2}{*}{ Middle East } & 38.2 & 41.8 & 42.0 & 42.0 & 42.0 & 8.4 & 3.8 & 2.5 & & 5.4 & 1.7 \\
\hline & \multicolumn{11}{|c|}{ Incomplete spells } \\
\hline Advanced & 30.3 & 30.2 & - & 30.3 & & 12.2 & 11.2 & & - & 13.8 & - \\
\hline Asia & 36.7 & 38.1 & - & 36.4 & & 2.0 & 4.4 & & - & 2.2 & - \\
\hline LA and Caribbean & 47.6 & 47.8 & - & 47.5 & & 3.8 & 1.5 & & - & 4.5 & - \\
\hline Africa & 42.7 & 43.3 & - & 43.6 & & 4.0 & 2.3 & & - & 4.5 & \\
\hline \multirow[t]{3}{*}{ Middle East } & 40.2 & 38.2 & - & 38.7 & & 1.5 & 1.1 & & - & 1.0 & - \\
\hline & \multicolumn{11}{|c|}{$\mathrm{h}=\mathbf{8}$} \\
\hline & \multicolumn{11}{|c|}{ Complete spells } \\
\hline Advanced & 31.8 & 30.0 & 30.2 & 31.8 & 30.0 & 14.3 & 15.1 & 16.7 & & 15.3 & 16.4 \\
\hline Asia & 41.1 & 40.2 & 40.1 & 39.7 & 40.0 & 8.3 & 7.9 & 7.7 & & 11.5 & 7.2 \\
\hline LA and Caribbean & 49.6 & 50.4 & 51.6 & 47.8 & 51.4 & 12.7 & 9.6 & 8.0 & & 11.7 & 7.9 \\
\hline Africa & & 48.2 & 48.8 & & 49.9 & & 0.9 & 0.0 & & & \\
\hline \multirow[t]{2}{*}{ Middle East } & 42.8 & 43.2 & 44.6 & 39.1 & 44.4 & 3.4 & 3.2 & 2.6 & & 2.9 & 1.7 \\
\hline & \multicolumn{11}{|c|}{ Incomplete spells } \\
\hline Advanced & 25.4 & 28.8 & - & 25.6 & & 9.3 & 8.5 & & - & 10.7 & - \\
\hline Asia & 34.5 & 37.5 & - & 34.1 & & 2.0 & 3.5 & & - & 2.2 & - \\
\hline LA and Caribbean & 49.5 & 47.9 & - & 49.2 & & 1.3 & 1.3 & & - & 1.6 & - \\
\hline Africa & 45.7 & 44.3 & - & 44.9 & & 4.1 & 2.8 & & - & 4.7 & - \\
\hline Middle East & 41.0 & 39.2 & - & 40.1 & & 1.7 & 1.4 & & - & 1.4 & - \\
\hline
\end{tabular}




\section{Table 5: Model Averaging Duration Analysis}

The table presents BMA results for the Cox duration model using the duration variable for $h=5$. The posterior inclusion probability (PIP) of a variable is the sum of the posterior probabilities models that include that variable. The posterior mean (PM) is the average of the partial likelihood coefficient estimates (COEF) of individual models weighted by posterior probability. The posterior standard error (PSE) is the BMA estimate for the standard error (SE) taking model uncertainty into account. It also presents four individual models of the BMA model space estimated by LS. The full model that includes all the determinants as well as the top three models having the highest posterior model probabilities. A great moderation time dummy, a sub-Saharan Africa dummy, and a high income country dummy were included in all models. All models include 627 observations, 57 subjects, and 20 failures. ${ }^{* * *}$, ${ }^{* *}$, and ${ }^{*}$ denote significance at $1 \%, 5 \%$, and $10 \%$, respectively.

\begin{tabular}{|c|c|c|c|c|c|c|c|c|c|c|c|c|}
\hline & & & IA Estin & ates & $\mathrm{Fu}$ & & Top & & Tol & & Top & \\
\hline & Variables & PIP & PM & PSE & COEF & SE & COEF & SE & COEF & SE & COEF & SE \\
\hline & Net Inequality & 96.9 & 0.0714 & 0.0390 & 0.0566 & 0.0474 & $0.0710^{* *}$ & 0.0360 & $0.0767^{* *}$ & 0.0343 & $0.0747^{* *}$ & 0.0336 \\
\hline & Redistribution & 32.5 & -0.0330 & 0.0677 & -0.1534 & 0.1062 & & & & & & \\
\hline & Income per capita & 99.6 & 0.5015 & 0.1901 & $0.6585^{* * *}$ & 0.2091 & $0.5451^{* * *}$ & 0.1616 & $0.4098^{* * *}$ & 0.1397 & $0.2618^{* *}$ & 0.1087 \\
\hline & Population & 10.5 & 0.0248 & 0.1068 & 0.3161 & 0.3244 & & & & & & \\
\hline & Investments & 63.8 & 1.3619 & 1.3067 & 1.9443 & 1.3389 & $2.3122^{* *}$ & 0.9159 & & & & \\
\hline & Primary Schooling & 0.4 & -0.0006 & 0.0213 & -0.1081 & 0.3963 & & & & & & \\
\hline & Growth During Spell & 54 & 0.0479 & 0.0634 & 0.0638 & 0.0708 & & $0.0957^{*}$ & 0.0532 & 0.0755 & & 0.0469 \\
\hline 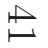 & Terms of Trade Growth & 23.4 & -0.0061 & 0.0152 & -0.0385 & 0.0276 & & & & & & \\
\hline & Shock to Terms of Trade Growth & 10.4 & -0.0802 & 0.3430 & -1.1117 & 0.8811 & & & & & & \\
\hline & US 3-month T-Bill Rate & 32.9 & 0.0868 & 0.1724 & 0.2794 & 0.2535 & & & & & & \\
\hline & Government & 14.7 & -0.0112 & 0.0423 & -0.0637 & 0.1011 & & & & & & \\
\hline & Openness & 34.1 & 0.0043 & 0.0077 & 0.0064 & 0.0104 & & & & $0.0144^{* *}$ & 0.0070 & \\
\hline & Inflation & 0.6 & -0.0001 & 0.0017 & -0.0160 & 0.0251 & & & & & & \\
\hline & Debt & 59.3 & 0.0041 & 0.0044 & 0.0051 & 0.0046 & $0.0073^{* *}$ & 0.0033 & & & & \\
\hline & FDI & 85.2 & -0.0350 & 0.0232 & $-0.0597^{* *}$ & 0.0267 & $-0.0390^{* *}$ & 0.0181 & $-0.0358 * *$ & 0.0160 & & \\
\hline & Ethnic & 51.4 & -0.0094 & 0.0138 & -0.0281 & 0.0175 & & & & & & \\
\hline & Executive Constraints & 0.6 & -0.0006 & 0.0156 & -0.2899 & 0.5553 & & & & & & \\
\hline & Democracy & 0.5 & -0.0002 & 0.0085 & 0.1564 & 0.3316 & & & & & & \\
\hline & Conflict & 0.7 & -0.0021 & 0.0719 & 0.2499 & 1.0637 & & & & & & \\
\hline & Market Distortions (PIPC) & 62.9 & 0.0091 & 0.0094 & 0.0128 & 0.0113 & $0.0155^{* *}$ & 0.0074 & & & & \\
\hline & LCR100KM & 8.7 & 0.0008 & 0.0043 & 0.0178 & 0.0148 & & & & & & \\
\hline & Posterior Model Probability & & & & 0 & & 0.04 & & 0.0 & & 0.029 & \\
\hline & Log Likelihood & & & & -41. & & -47.8 & & -49 & & -52.7 & \\
\hline
\end{tabular}


Table 6: Non-linear effects

The table presents BMA results for the Cox duration model using the duration variable for $h=5$. The posterior inclusion probability (PIP) of a variable is the sum of the posterior probabilities models that include that variable. The posterior mean (PM) is the average of the partial likelihood coefficient estimates (COEF) of individual models weighted by posterior probability. The posterior standard error (PSE) is the BMA estimate for the standard error (SE) taking model uncertainty into account. A great moderation time dummy, a sub-Saharan Africa dummy, and a high income country dummy were included in all models. All models include 627 observations, 57 subjects, and 20 failures.

\section{Variables}

Net Inequality

Redistribution

Net Inequality - Bottom $70 \%$

Net Inequality - Top 30\%

Redistribution - Bottom 70\%

Redistribution - Top 30\%

Income per capita

Population

Investments

Primary Schooling

Secondary Schooling

Growth During Spell

Terms of Trade Growth

Shock to Terms of Trade Growth

US 3-month T-Bill Rate

Government

Openness

Inflation

Overvaluation

Debt

FDI

Ethnic

Executive Constraints

Democracy

Conflict

Market Distortions (PIPC)

LCR100km
Both Inequality

Redistribution

PIP PM PSE

$-$

$93.1-0.1408 \quad 0.0697$

$\begin{array}{lll}8.3 & -0.0072 & 0.0390\end{array}$

$\begin{array}{lll}1.3 & -0.0002 & 0.0088\end{array}$

$\begin{array}{lll}100 & 0.5475 & 0.1828\end{array}$

$\begin{array}{lll}16.2 & 0.0418 & 0.1350\end{array}$

$80.5 \quad 1.7710 \quad 1.2796$

$\begin{array}{lll}5.5 & -0.0149 & 0.0958\end{array}$

$\begin{array}{lll}99.8 & -1.3090 & 0.5537\end{array}$

$\begin{array}{lll}36.5 & 0.0300 & 0.0548\end{array}$

$\begin{array}{llll}39.9 & -0.0134 & 0.0223\end{array}$

$\begin{array}{lll}20 & -0.2032 & 0.5565\end{array}$

$\begin{array}{lll}26.7 & 0.0781 & 0.1731\end{array}$

$\begin{array}{lll}2.5 & -0.0009 & 0.0169\end{array}$

$\begin{array}{lll}39 & 0.0051 & 0.0085\end{array}$

$\begin{array}{lll}1.5 & 0.0000 & 0.0026\end{array}$

$\begin{array}{lll}2.4 & 0.0001 & 0.0013\end{array}$

$\begin{array}{lll}39.9 & 0.0023 & 0.0036\end{array}$

$\begin{array}{lll}96.3 & -0.0415 & 0.0213\end{array}$

$\begin{array}{lll}48.3 & -0.0097 & 0.0148\end{array}$

$\begin{array}{lll}4.1 & -0.0058 & 0.0486\end{array}$

$\begin{array}{lll}3.4 & -0.0023 & 0.0262\end{array}$

$\begin{array}{lll}3.5 & -0.0138 & 0.2014\end{array}$

$82.4 \quad 0.0143 \quad 0.010$

$\begin{array}{lll}54.3 & 0.0092 & 0.0121\end{array}$
Inequality

$\begin{array}{rrr}\text { PIP } & \text { PM } & \text { PSE } \\ & & - \\ - & - & - \\ 5.5 & -0.0027 & 0.0235 \\ 98.4 & 0.1944 & 0.0840 \\ 98.4 & 0.1490 & 0.0626 \\ - & - & - \\ - & - & - \\ 100 & 0.5545 & 0.1823 \\ 14.2 & 0.0361 & 0.1267 \\ 82 & 1.7640 & 1.2573 \\ 6.9 & -0.0176 & 0.1043 \\ 99.8 & -1.2900 & 0.5528 \\ 35.2 & 0.0286 & 0.0542 \\ 37.3 & -0.0125 & 0.0217 \\ 20.8 & -0.2045 & 0.5553 \\ 29.3 & 0.0848 & 0.1780 \\ 2.2 & 0.0002 & 0.0129 \\ 44.2 & 0.0058 & 0.0088 \\ 2.5 & -0.0001 & 0.0035 \\ 3.4 & 0.0001 & 0.0015 \\ 37.9 & 0.0021 & 0.0035 \\ 96.9 & -0.0428 & 0.0213 \\ 47.9 & -0.0097 & 0.0148 \\ 5.8 & -0.0078 & 0.0556 \\ 4.6 & -0.0029 & 0.0290 \\ 3.1 & -0.0018 & 0.1796 \\ 85.7 & 0.0149 & 0.0100 \\ 62.6 & 0.0106 & 0.0124\end{array}$

Redistribution

$\begin{array}{rrr}\text { PIP } & \text { PM } & \text { PSE } \\ 94.6 & 0.0705 & 0.0403 \\ - & - & - \\ - & - & - \\ - & - & - \\ 8.1 & -0.0080 & 0.0413 \\ 8 & -0.0050 & 0.0275 \\ 100 & 0.5011 & 0.1850 \\ 12.4 & 0.0292 & 0.1132 \\ 66.8 & 1.3900 & 1.3056 \\ 2 & -0.0022 & 0.0437 \\ 100 & -1.4030 & 0.5487 \\ 61.4 & 0.0536 & 0.0650 \\ 25.8 & -0.0063 & 0.0151 \\ 9.7 & -0.0653 & 0.3115 \\ 37.8 & 0.1037 & 0.1850 \\ 19.1 & -0.0152 & 0.0480 \\ 27.9 & 0.0035 & 0.0072 \\ 1 & 0.0000 & 0.0019 \\ 4.5 & 0.0003 & 0.0019 \\ 62.4 & 0.0042 & 0.0044 \\ 89.4 & -0.0345 & 0.0218 \\ 65.5 & -0.0120 & 0.0145 \\ 1.5 & -0.0006 & 0.0206 \\ 1.5 & -0.0003 & 0.0128 \\ 2.3 & -0.0050 & 0.1228 \\ 59.8 & 0.0086 & 0.0093 \\ 9 & 0.0009 & 0.0043\end{array}$


Table 7: Robustness - Dropping Channels

The table presents BMA results for the Cox duration model using the duration variable for $h=5$. The posterior inclusion probability (PIP) of a variable is the sum of the posterior probabilities models that include that variable. The posterior mean (PM) is the average of the partial likelihood coefficient estimates (COEF) of individual models weighted by posterior probability. A great moderation time dummy, a sub-Saharan Africa dummy, and a high income country dummy were included in all models. All models include 627 observations, 57 subjects, and 20 failures.

\begin{tabular}{|c|c|c|c|c|c|c|c|c|c|c|c|c|c|c|}
\hline \multirow[b]{2}{*}{ Variables } & \multicolumn{2}{|c|}{ Schooling } & \multicolumn{2}{|c|}{ Institutions } & \multicolumn{2}{|c|}{ Shocks } & \multicolumn{2}{|c|}{ Government } & \multicolumn{2}{|c|}{ Distortions } & \multicolumn{2}{|c|}{ Conflict } & \multicolumn{2}{|c|}{ Ethnic } \\
\hline & PIP & PM & PIP & PM & PIP & $\mathbf{P M}$ & PIP & PM & PIP & PM & PIP & PM & PIP & PM \\
\hline Net Inequality & 99.9 & 0.0673 & 99.7 & 0.0771 & 98.7 & 0.0682 & 96.9 & 0.0745 & 92.9 & 0.0686 & 96.7 & 0.0710 & 88.7 & 0.0645 \\
\hline Redistribution & 53 & -0.0556 & 39.7 & -0.0413 & 25.2 & -0.0227 & 32.1 & -0.0346 & 45 & -0.0464 & 34.9 & -0.0355 & 28.3 & -0.0286 \\
\hline Income per capita & 100 & 0.3359 & 99.2 & 0.4623 & 99.8 & 0.3032 & 99.2 & 0.4222 & 99.3 & 0.4202 & 99.5 & 0.5055 & 99.8 & 0.4898 \\
\hline Population & 0.7 & 0.0007 & 10.7 & 0.0241 & 5.1 & 0.0081 & 5.1 & 0.0082 & 4.8 & 0.0116 & 10.6 & 0.0255 & 13.2 & 0.0264 \\
\hline Investments & 100 & 1.9220 & 22.5 & 0.3502 & 82.7 & 1.4842 & & & 7.1 & 0.0816 & 66 & 1.4127 & 64.5 & 1.3099 \\
\hline Primary Schooling & & & 2 & -0.0026 & 1.9 & 0.0024 & 2.3 & -0.0033 & 1.1 & -0.0019 & 0.7 & -0.0007 & 3.6 & -0.0017 \\
\hline Secondary Schooling & & & 99.7 & -1.3155 & 99.8 & -1.0985 & 99.6 & -1.2897 & 99.3 & -1.3039 & 99.8 & -1.3693 & 99.9 & -1.3413 \\
\hline Growth During Spell & 19.9 & 0.0137 & 98.1 & 0.1020 & 60.9 & 0.0509 & 85.4 & 0.0851 & 88.1 & 0.0876 & 51.7 & 0.0456 & 52 & 0.0419 \\
\hline Terms of Trade Growth & 37.9 & -0.0098 & 32.2 & -0.0090 & & & 25.6 & -0.0078 & 31 & -0.0097 & 24.3 & -0.0063 & 28.8 & -0.0072 \\
\hline Shock to Terms of Trade Growth & 6.2 & -0.0422 & 8.2 & -0.0577 & & & 3.5 & -0.0171 & 5.3 & -0.0361 & 10.9 & -0.0843 & 8.7 & -0.0461 \\
\hline US 3-month T-Bill Rate & 32.1 & 0.0899 & 37.4 & 0.1069 & & & 25.4 & 0.0653 & 24.1 & 0.0641 & 33.8 & 0.0886 & 28.6 & 0.0688 \\
\hline Government & 3.2 & -0.0024 & 12.5 & -0.0084 & 5.3 & -0.0021 & & & 15.4 & -0.0137 & 15.4 & -0.0116 & 15.1 & -0.0120 \\
\hline Openness & 0.3 & 0.0000 & 76.7 & 0.0107 & 10.2 & 0.0010 & 70.6 & 0.0099 & 65.3 & 0.0091 & 33 & 0.0042 & 42.8 & 0.0052 \\
\hline Inflation & 0.3 & 0.0000 & 1.9 & -0.0001 & 1.7 & -0.0001 & 2.1 & -0.0001 & 2.1 & -0.0002 & 1.5 & -0.0001 & 4.1 & -0.0001 \\
\hline Overvaluation & 0.3 & 0.0000 & 15.4 & 0.0014 & 3.8 & 0.0001 & 20.1 & 0.0018 & 14.6 & 0.0014 & 7.3 & 0.0006 & 9.4 & 0.0006 \\
\hline Debt & 98.2 & 0.0069 & 21 & 0.0008 & 39.8 & 0.0022 & 16.2 & 0.0006 & 21.5 & 0.0011 & 61.8 & 0.0043 & 60.7 & 0.0041 \\
\hline FDI & 100 & -0.0532 & 97.9 & -0.0378 & 53.4 & -0.0198 & 84 & -0.0311 & 74.3 & -0.0302 & 85.8 & -0.0355 & 88.5 & -0.0354 \\
\hline Ethnic & 0.9 & -0.0001 & 77 & -0.0147 & 42.1 & -0.0070 & 37.8 & -0.0070 & 52.5 & -0.0100 & 49.1 & -0.0090 & & \\
\hline Executive Constraints & 4.8 & -0.0060 & & & 8.3 & -0.0092 & 4.5 & -0.0047 & 1.7 & -0.0019 & 0.8 & -0.0007 & 5.9 & -0.0045 \\
\hline Democracy & 2.7 & -0.0013 & & & 6 & -0.0030 & 5.1 & -0.0033 & 1.6 & -0.0011 & 0.6 & -0.0003 & 7.3 & -0.0034 \\
\hline Conflict & 1.7 & 0.0074 & 3.4 & -0.0120 & 2.3 & -0.0095 & 3.5 & -0.0145 & 1.8 & -0.0065 & & & 6.3 & -0.0220 \\
\hline Market Distortions (PIPC) & 100 & 0.0169 & 22.5 & 0.0024 & 72.8 & 0.0101 & 6.9 & 0.0004 & & & 64.8 & 0.0094 & 65 & 0.0089 \\
\hline LCR100km & 48.2 & 0.0063 & 10.5 & 0.0012 & 18.3 & 0.0020 & 7 & 0.0007 & 4.8 & 0.0005 & 8 & 0.0008 & 9.4 & 0.0008 \\
\hline
\end{tabular}


Table 8: Robustness - Keeping Channels

The table presents BMA results for the Cox duration model using the duration variable for $h=5$. The posterior inclusion probability (PIP) of a variable is the sum of the posterior probabilities models that include that variable. The posterior mean (PM) is the average of the partial likelihood coefficient estimates (COEF) of individual models weighted by posterior probability. A great moderation time dummy, a sub-Saharan Africa dummy, and a high income country dummy were included in all models. All models include 627 observations, 57 subjects, and 20 failures.

Net Inequality

Redistribution

Income per capita

Population

Investments

Primary Schooling

Secondary Schooling

Growth During Spell

Terms of Trade Growth

I Shock to Terms of Trade Growth

US 3-month T-Bill Rate

Government

Openness

Inflation

Overvaluation

Debt

FDI

Ethnic

Executive Constraints

Democracy

Conflict

Market Distortions (PIPC)

LCR100KM

\begin{tabular}{|c|c|c|c|c|c|c|c|c|c|c|c|c|c|}
\hline \multicolumn{2}{|c|}{ Schooling } & \multicolumn{2}{|c|}{ Institutions } & \multicolumn{2}{|c|}{ Shocks } & \multicolumn{2}{|c|}{ Government } & \multicolumn{2}{|c|}{ Distortions } & \multicolumn{2}{|c|}{ Conflict } & \multicolumn{2}{|c|}{ Ethnic } \\
\hline PIP & $P M$ & PIP & $\mathbf{P M}$ & IP & $\mathbf{P M}$ & PIP & PM & PIP & PM & PIP & PM & PIP & PM \\
\hline 9.1 & 0.0698 & 3.4 & 0.0509 & . & 0.0525 & 4.8 & 0.0637 & 99.5 & 0.0726 & 99.4 & 0.0717 & 97.2 & 0.0733 \\
\hline 66.9 & -0.0800 & 99.1 & -0.1428 & 66.3 & -0.0842 & 30 & -0.0290 & 35.4 & -0.0350 & 35.7 & -0.0431 & 33 & -0.0352 \\
\hline 100 & 0.5803 & 100 & 0.6391 & 100 & 0.5780 & 100 & 0.5713 & 100 & 0.5491 & 100 & 0.5165 & 100 & 0.5169 \\
\hline 28.1 & 0.0860 & 71.9 & 0.2578 & 24.6 & 0.0664 & 4.2 & 0.0098 & 13 & 0.0309 & 8.1 & 0.0239 & 15 & 0.0372 \\
\hline 76.4 & 1.5177 & 92.7 & 2.0806 & 82.7 & 1.7393 & 100 & 2.1330 & 98.1 & 2.1250 & 31.9 & 0.7228 & 54.2 & 1.1527 \\
\hline 100 & -0.1434 & 6.1 & -0.0055 & 6.9 & -0.0098 & 1.1 & -0.0014 & 0.4 & -0.0004 & 0.6 & -0.0009 & 1 & -0.0014 \\
\hline 100 & -1.3183 & 100 & -1.2783 & 100 & -1.3709 & 100 & -1.4770 & 100 & -1.3970 & 100 & -1.4490 & 100 & -1.4035 \\
\hline 77.6 & 0.0649 & 48.5 & 0.0338 & 57.8 & 0.0510 & 27.2 & 0.0192 & 27.1 & 0.0 & 84.7 & 0.0826 & 68.7 & 0.0652 \\
\hline 79 & -0.0267 & 91.2 & -0.0298 & 100 & -0.0302 & 30 & -0.0082 & 18.6 & -0.0041 & 31.9 & -0.0093 & 32.9 & -0.0089 \\
\hline 46.7 & -0.4412 & 99. & -1.1604 & 100 & -0.9399 & 22.1 & -0.2128 & 14.5 & -0.1117 & 27.9 & -0.2657 & 17.2 & -0.1377 \\
\hline 84.3 & 0.2443 & 75 & 0.2200 & 100 & 0.2833 & 54 & 0.1 & 36.9 & 0.0 & 36.4 & 0.1047 & 40.7 & 0.1124 \\
\hline 32.5 & -0.0315 & 23.6 & -0.0190 & 45.2 & -0.0486 & 100 & -0.0646 & 12.9 & -0.0082 & 14 & -0.0140 & 15.7 & -0.0124 \\
\hline 35.9 & 0.0046 & 24.1 & 0.0023 & 30 & 0.0033 & 26.2 & 0.0023 & 15.1 & 0.0013 & 70 & 0.0101 & 42 & 0.0054 \\
\hline 2.7 & -0.0004 & 13 & -0.0018 & 4.9 & -0.0004 & 0.7 & -0.0001 & 0.5 & 0.0000 & 0.5 & -0.0001 & 1.2 & -0.0001 \\
\hline 36.4 & 0.0036 & 28.6 & 0.0025 & 20.5 & 0.0017 & 1.2 & 0.0001 & 4.2 & 0.0002 & 8.9 & 0.0008 & 10 & 0.0009 \\
\hline 84 & 0.0052 & 83.8 & 0.0052 & 81.9 & 0.0058 & 99.7 & 0.0077 & 82.1 & 0.0058 & 39.1 & 0.0025 & 53.9 & 0.0036 \\
\hline 100 & -0.0450 & 100 & -0.0519 & 100 & -0.0462 & 100 & -0.0435 & 88.8 & -0.0375 & 100 & -0.0430 & 91.7 & -0.0374 \\
\hline 100 & -0.0223 & 100 & -0.0264 & 91 & -0.0217 & 45.6 & -0.0087 & 42.5 & -0.0076 & 100 & -0.0179 & 100 & -0.0183 \\
\hline 2.7 & -0.0029 & 100 & -0.3806 & 8.5 & -0.0115 & 0.6 & -0.0004 & 0.4 & -0.0003 & 1.6 & -0.0020 & 1.2 & -0.0011 \\
\hline 2.1 & -0.0007 & 100 & 0.1779 & 7.1 & -0.0022 & 0.4 & -0.0001 & 0.2 & 0.0000 & 1.2 & -0.0009 & 0.9 & -0.0004 \\
\hline 2 & 0.0058 & 6 & 0.0047 & 5 & 0.0027 & 0.4 & 0.0008 & 0.3 & 0.0004 & 100 & -0.2414 & 1.5 & -0.0041 \\
\hline 57.9 & 0.0074 & 85.7 & 0.0136 & 70.2 & 0.0093 & 94.7 & 0.0139 & 100 & 0.0145 & 30.5 & 0.0044 & 52.2 & 0.0071 \\
\hline 32.8 & 0.0049 & 69.2 & 0.0110 & 31.6 & 0.0044 & 7.4 & 0.0008 & 10.7 & 0.0010 & 12 & 0.0017 & 11.1 & 0.0012 \\
\hline
\end{tabular}


Appendix 


\section{Table A1: Data Appendix}

\section{Variable}

Net Inequality

Redistribution

Income per capita.

Population

Investments

Primary schooling

Secondary schooling

Growth During Spell

Population Growth

Investment Growth

Growth of Export to Import Prices

US 3-month T-Bill Rate

Terms of Trade Growth

Oil Price Growth

Government

Openness

Inflation

Overvaluation

Debt

\section{FDI}

Executive Constraints

\section{Democracy}

Ethnic Fractionalization

Distortions

Conflict

\section{LCR100km}

Great moderation

Sub-Saharan Africa dummy

High income country dummy

\section{Description}

Gini Coefficient for net inequality (inequality after taxes and transfers). Source: Solt (2009). SWIID 3.1.

Difference between the Gini coefficient for market and for net inequality Source: Solt (2009). SWIID 3.1.

Log real GDP per capita (2000 US dollars at PPP). Source: PWT 7.1.

Log population. Source: PWT 7.1.

Log of real investment as ratio to GDP (2005 US dollars at PPP). Source: PWT 7.1.

Average years of total primary school attainment $(15+)$. Source: Barro and Lee.

Logarithm of average years of total secondary school attainment (15+). Source: PWT 7.1.

Annual growth rate of GDP per capita. Source: PWT 7.1.

Annual population growth rate. Source: PWT 7.1.

Annual growth of real investment as ratio to GDP (2005 US dollars at PPP) PWT 7.1.

Growth rate of the ratio of export prices to import prices. Source: WEO.

3 month Treasury bill. Source: FRED.

Growth rate of the terms of trade. Source: WEO.

Growth rate of oil price. Source: IFS.

Government spending as a share of GDP. Source: PWT 7.1.

Ratio of exports plus imports to GDP, PPP adjusted, in 2005 prices. Source: PWT 7.1.

Log inflation computed as $100 * \ln (1+$ inflation/100). Source: IFS

Residuals of year-by-year cross-sectional regressions of log price level of GDP on log per capita income, in percent. Source: PWT 7.1.

External debt liabilities from IMF's (WEO) and World Bank's Global Development Finance database. Source: Lane and Milesi-Ferretti (2002).

Data on foreign assets and liabilities of banks and other banking. Source: Lane and Milesi-Ferretti (2002).

A measure of the extent of institutionalized constraints on the decision making powers of chief executives. This variable ranges from zero to one where higher values equal a greater extent of institutionalized constraints on the power of chief executives. Source: POLITY IV.

Level of institutionalized democracy. This variable ranges from zero to ten where higher values equal a greater extent of institutionalized democracy. Source: POLITY IV.

Measure of linguistic fractionalization based on data describing shares of languages spoken as "mother tongues". Source: Alesina, Devleeschauwer, Easterly, Kurlat, and Wacziarg (2003).

Ratio of Price Level of Investment/Price Level of Consumption. Source Penn 7.1.

Indicator variable with a value of 1 if a country is involved in intrastate or interstate conflict. Source: UCDP (Uppsala Conflict Data Program)/PRIO Armed Conflict Dataset

Percentage of a country's land area within $100 \mathrm{~km}$ of an ice- free coast. Source: The Center for International Development at Harvard University.

Indicator variable with value of 1 if year greater than or equal to 1985. Authors' calculation.

Indicator variable ith a value of 1 for sub-Saharan African countries. Authors' calculation.

Indicator variable with a value of 1 for advanced countries. Authors' calculation. 